\title{
Rafael Obregón Loría, el historiador del siglo XIX
}

\author{
Rafael A. Méndez Alfaro \\ Licenciado en Historia. Coordinador del Programa de Estudios Generales de la Universidad Estatal a \\ Distancia (UNED), Costa Rica. Correo electrónico: ramendez@uned.ac.cr
}

\section{Silvia Elena Molina Vargas}

Maestría en Historia. Profesora de la Escuela de Historia de la Universidad de Costa Rica. Correo eletrónico: silviamolinav@yahoo.com

Fecha de recibido: 3 de septiembre de 2015 - Fecha de aceptación: 2 de noviembre de 2015

\author{
Palabras claves \\ Rafael Obregón Loría, historia, humanismo, Costa Rica
}

Keywords

Rafael Obregón Loría, history, humanism, Costa Rica

\begin{abstract}
Resumen
El trabajo que se presenta ofrece una visión general de la vida y obra del notable historiador y humanista costarricense, Rafael Obregón Loría. Se subrayan asuntos relacionados con sus orígenes familiares, formación, intereses disciplinarios, obra producida y reconocimientos de los que fue objeto. Pretende ser una aproximación inicial al hombre que se movió entre la historia del siglo XIX, los estudios de masonería y el análisis de la Campaña Nacional contra los filibusteros (1856-1857), promoviendo el estudio del pasado como un sustento básico de la identidad costarricense.
\end{abstract}

\begin{abstract}
The work presented here provides an overview of the life and work of the notable Costa Rican historian and humanist Rafael Obregón Loría, highlighting his family background, his training, his disciplinary interests, and the production and recognition of his work. Obregón Loría has evolved from writing history of the nineteenth century approach to Freemasonry studies and an analysis of the National Campaign against the filibusters (1856-1857), promoting the study of the past as a basic livelihood of the Costa Rican identity. It is complemented by representative photographic material from a set of events and academic scholarship linked to Obregón Loría.
\end{abstract}

\section{Introducción}

Hacia mediados del año 2009, fuimos invitados por la Comisión de Facultades Humanísticas de Centroamérica y del Caribe (COFAHCA) a presentar una ponencia sobre el historiador Rafael Obregón Loría en el marco del III Congreso de Pensadores y Pensadoras Humanistas de Centroamérica y del Caribe, efectuado en la Universidad Nacional de Costa Rica. En ese momento, acogimos la propuesta, en representación de la Universidad Estatal a Distancia, con gran entusiasmo por cuanto la figura que se nos ofrecía para analizar, constituía no solo un gran historiador del país, sino porque en esencia, era un pensador humanista de primer orden, cuya impronta se ha dejado sentir en la Costa Rica de la segunda mitad del siglo XX hasta nuestros días. 
Imagen 1

Rafael Obregón Loría (1911-2000), s. f.

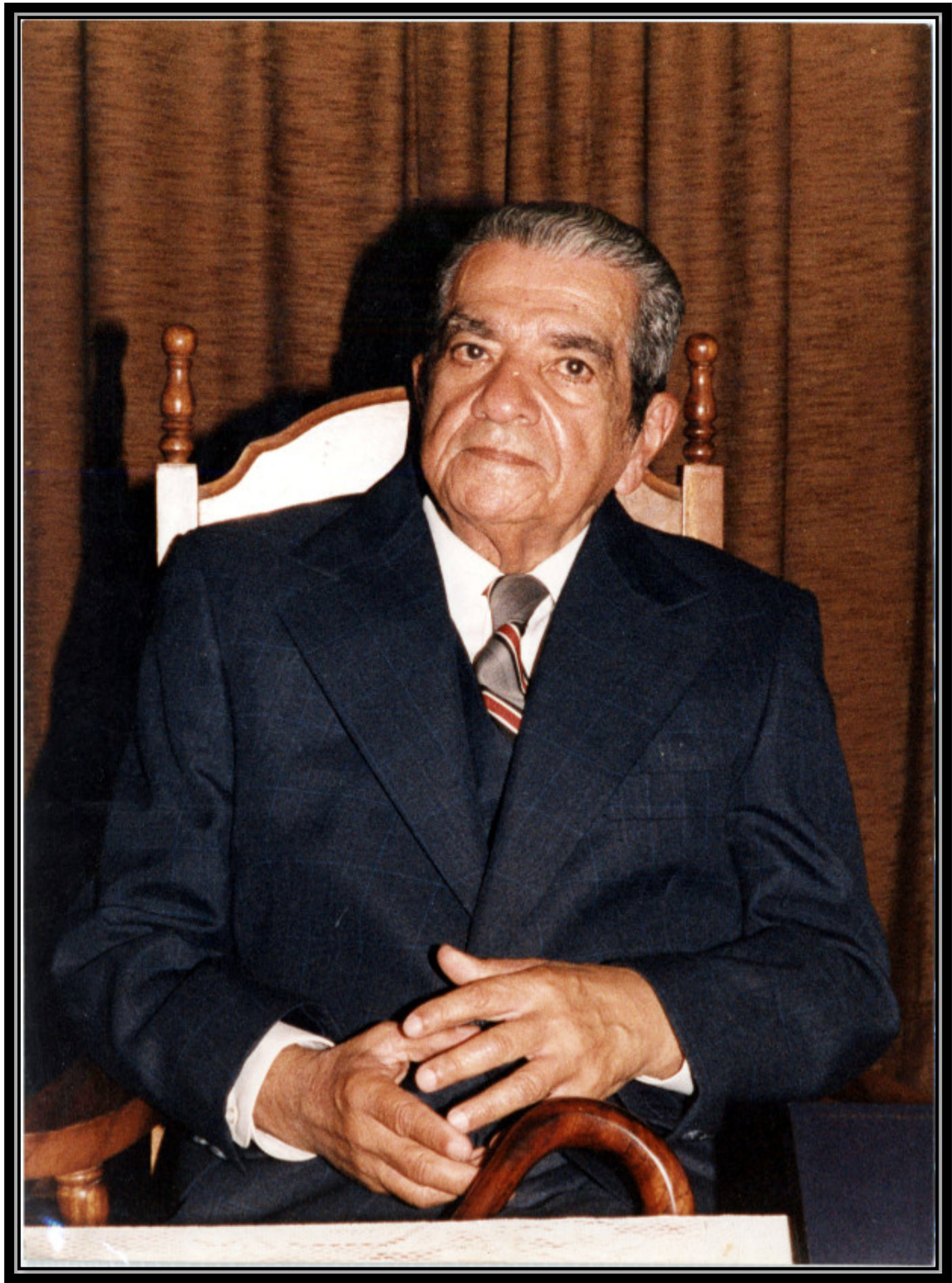

Fuente: Museo Histórico Cultural Juan Santamaría. 
El estudio de la obra de Obregón Loría nos llevó a una búsqueda sistemática de información relacionada con su vida y con su quehacer. Fue necesario revisar con meticulosidad diversas fuentes que nos ofrecieran una visión aproximada de la dimensión que tuvo el trabajo universitario y la producción historiográfica del destacado profesor de Estado.

El ensayo que hoy se presenta lleva brinda una imagen general de las grandes líneas de trabajo y de acción desplegadas por el estudioso universitario y el investigador acucioso. Se destaca su trayectoria, logros y aportes esenciales, tanto para la disciplina histórica en particular, como para la sociedad costarricense en términos generales.

Es menester señalar que el presente trabajo constituye una primera aproximación a la vida y obra de Rafael Obregón Loría, subrayando las diversas facetas e intereses de investigación que desarrolló a lo largo de su vida. Como parte de este trabajo se incluyen, en formato de anexos, un conjunto de ilustraciones asociadas a eventos académicos significativos en la fértil trayectoria del historiador y humanista Obregón Loría.

\section{Imagen 2}

Rafael Obregón Loría (1911-2000), s. f.

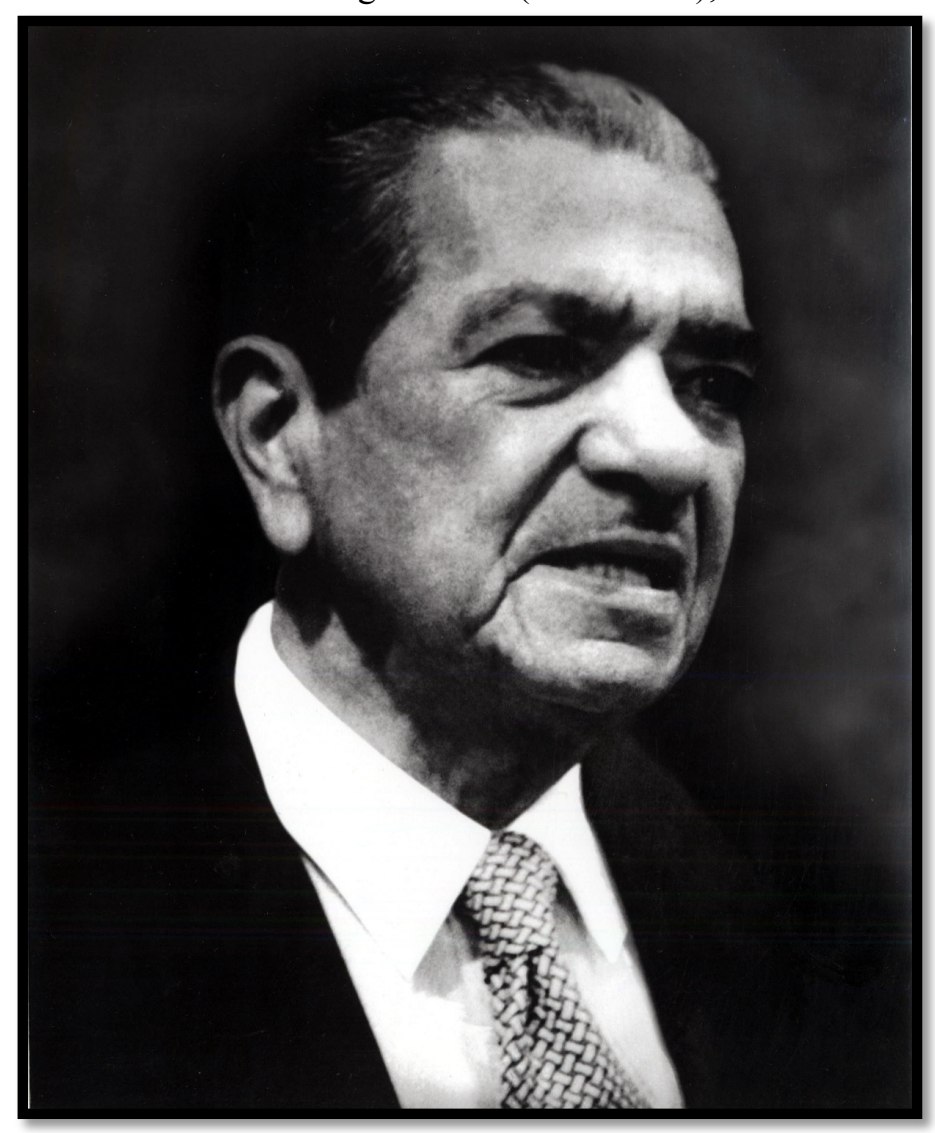

Fuente: Museo Histórico Cultural Juan Santamaría. 


\section{Una mirada al ser humano y profesional}

El día 9 de julio de 1911 nacía en la ciudad de San José el noveno hijo de un reconocido matrimonio costarricense. El nombre del niño era Fernando Rafael Obregón Loría y sus padres eran Miguel Obregón Lizano ${ }^{1}$ y Clotilde Loría Iglesias.

Este matrimonio, de origen alajuelense y josefino, se conformó en 1894 por personas conocidas dentro del ámbito nacional. Él había ocupado el cargo de Secretario de Instrucción Pública, fue bibliotecario de la Universidad de Santo Tomás (institución que vio cerrar sus puertas en 1888), y se convertiría, además, en una pieza fundamental en la creación y organización de la Biblioteca Nacional; entidad que en la actualidad lleva su nombre. Por su parte, Clotilde Loría era descendiente del Auditor de guerra en la Campaña de Tránsito².

Los Obregón Loría integraron una numerosa familia: concibieron catorce hijos, de los cuales sobrevivieron once. Al respecto, Mercedes Obregón Loría, hermana de Rafael, relataba parte de su cotidianeidad:

Nosotros éramos una familia muy numerosa: once hijos. Siempre nos sentábamos trece a la mesa: por este motivo cuando alguien decía que trece es número de mal agüero, a nosotros nos daba risa. Y siempre, naturalmente nuestro padre tenía escasez de dinero ${ }^{3}$.

En medio de esta copiosa familia emplazada en Barrio Amón, habitando una casa antigua pero de corte elegante y rodeado de profusos textos, fue creciendo Rafael Obregón. Cursó sus estudios primarios en la escuela Juan Rudín y más tarde, en 1931, obtuvo su título de Bachiller en Ciencias y Letras en el Liceo de Costa Rica.

\footnotetext{
${ }^{1}$ Nació en la ciudad de Alajuela el 19 de julio de 1861. Se graduó de Bachiller en Filosofía en la Universidad de Santo Tomás. Fue profesor de Geografía en el Liceo de Costa Rica, Jefe de Educación Primaria en calidad de recargo de sus funciones de Oficial Mayor del Ministerio de Educación. Aficionado como era a la geografía y cartografía, confeccionó numerosos mapas de Costa Rica que han sido de inmensa utilidad en las escuelas y colegios del país. Pocos días antes de su muerte el Magisterio Nacional lo declaró Benemérito de la Enseñanza. La Asamblea Legislativa le otorgó el título de Benemérito de la Patria por acuerdo \#272 de 18 de mayo de 1959. Murió en la ciudad de San José el 24 de julio de 1935. Asamblea Legislativa, República de Costa Rica, "Beneméritos de la Patria, Miguel Obregón Lizano" (2009 [citado el 3 de septiembre de 2015]): disponible en http://www.asamblea.go.cr/Centro de informacion/Sala Audiovisual/Benemritos\%20de\%201a\%20patria/For ms/DispForm.aspx?ID=33

${ }^{2}$ Mata, "Infatigable maestro", La Nación (8 de mayo del 2000), 14A.

3 "Eran otros tiempos", La Nación (1º de enero de 1975), s.p.
} 


\section{Imagen 3}

La familia Obregón Loría y los hijos que llegaron a adultos, s.f.

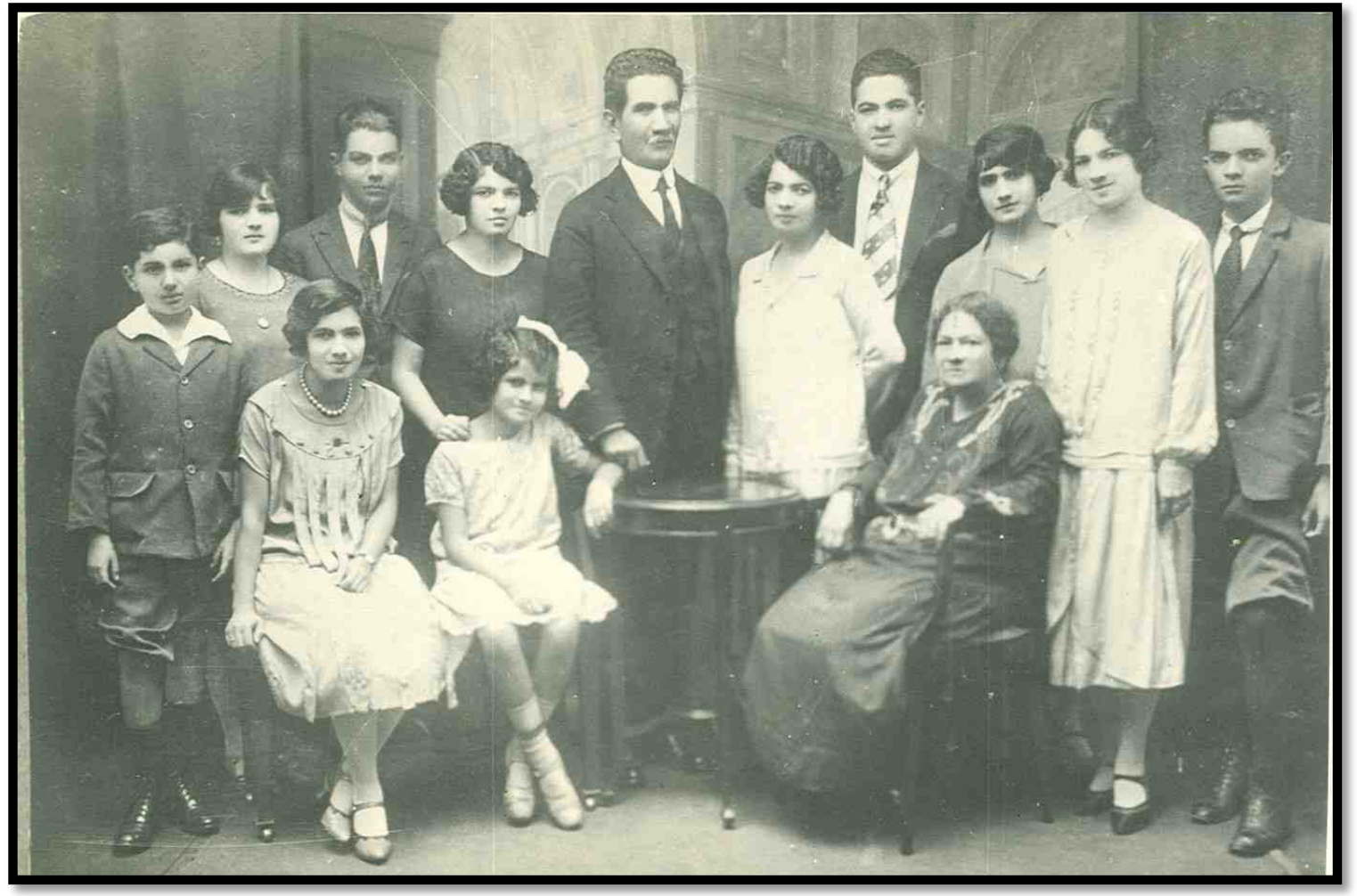

Fuente: Sistema Nacional de Bibliotecas Costa Rica (SINABI [citado el 3 de septiembre de 2015]): disponible en http://www.sinabi.go.cr/BibliotecaDigital/FOTOS/personajes.html

Simultáneamente a su preparación en estos centros educativos, Obregón se veía cada vez más interesado en ampliar sus conocimientos en las áreas de historia, geografía y astronomía. Esta pretensión se explica por la atracción que su padre sentía sobre esos saberes, de tal modo que conforme transcurría el tiempo, este ambiente se iba traduciendo en una significativa influencia sobre él. A lo anterior se le debe aunar la pasión que Rafael Obregón profesaba por la lectura; circunstancias que en su conjunto le permitieron ir modelando su perfil autodidacta.

Obregón fue un estudiante aventajado en sus estudios. Esta situación le permitió que tras una breve separación del Liceo, luego de haber obtenido su título de bachiller, se reincorporara nuevamente al plantel educativo en 1933; sólo que en esta ocasión como profesor. Iniciaba de este modo su recorrido por diversas instituciones secundarias como sucedió con el referido Liceo de Costa Rica, el Colegio Superior de Señoritas, el Colegio Omar Dengo y el Colegio Nuestra Señora de Sión. 


\section{Imagen 4}

Miguel Obregón con sus hijos Miguel, Francisco, Édgar A. y Rafael, s.f.

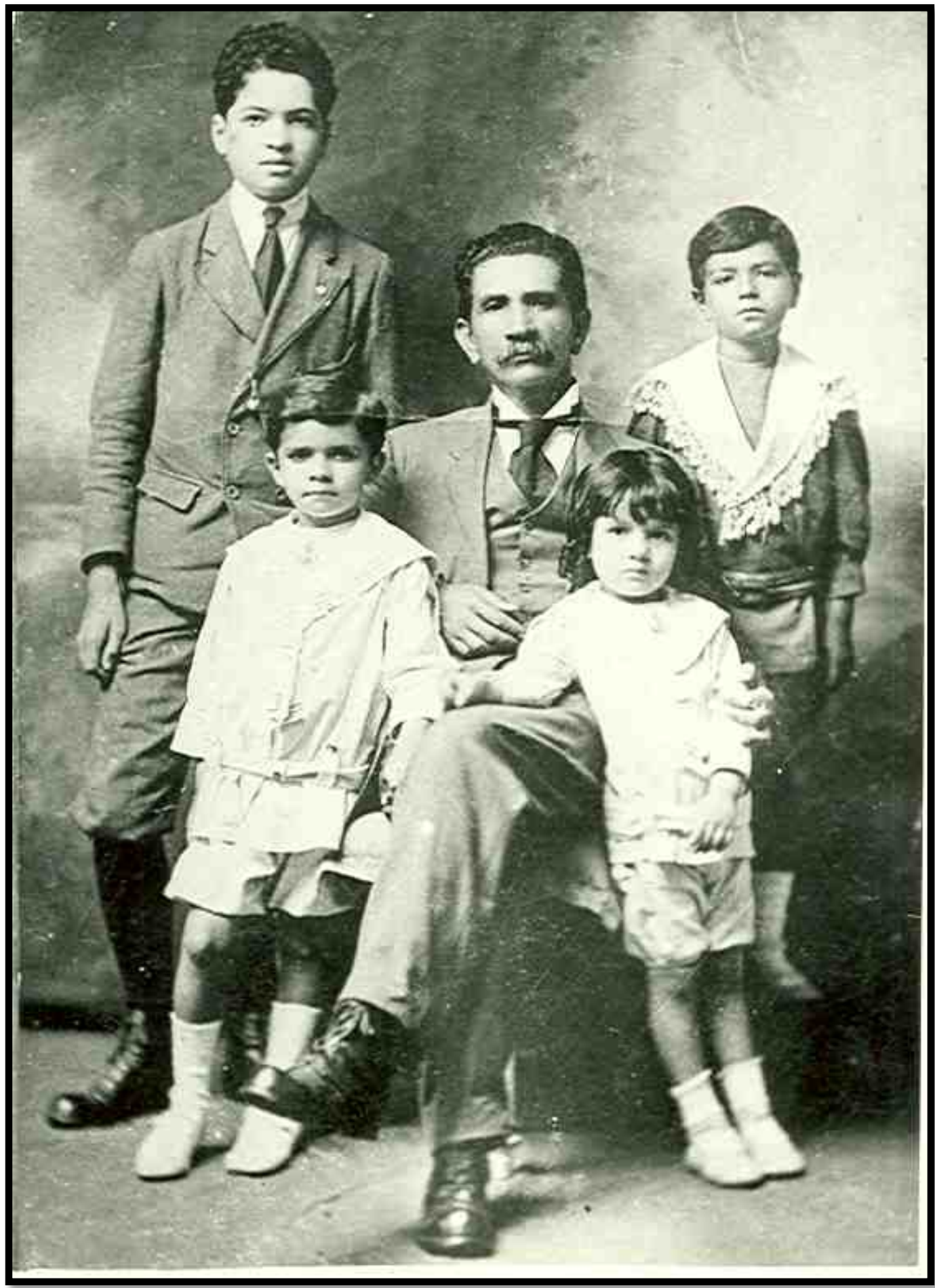

Fuente: Sistema Nacional de Bibliotecas Costa Rica (SINABI[citado el 3 de septiembre de 2015]): disponible http://www.sinabi.go.cr/BibliotecaDigital/FOTOS/personajes.html 
En un primer momento impartió en dichos centros las lecciones de cosmografía, más tarde serían clases de matemáticas, geografía e historia. Además, "allí conoció a profesores de la talla de León Pacheco, Arturo Agüero y Carlos Monge Alfaro"4. Como él mismo afirmaba respecto a su experiencia docente adquirida entre los años 1933 y hasta 1955: "Fueron años largos y agradables que no habría interrumpido si hubiera estado en sus manos"5.

Pero no sólo impartió lecciones en Costa Rica, en su momento Obregón se desplazó a Canadá para visitar a uno de sus hermanos, sin embargo se quedó en ese país pues asumió el cargo de profesor de español ${ }^{6}$ en el Assumption College, de Ontario; lo anterior por espacio de un $a_{n}{ }^{7}$ y donde ofreció además algunas cátedras ${ }^{8}$. De igual modo, laboró en pedagogía en Estados Unidos, Perú, Chile y Nicaragua9 .

Dos importantes eventos marcarían a Rafael Obregón Loría. El primero de ellos sucedió en marzo de 1943, fecha en que contrajo matrimonio con la también educadora Luz Argentina Brenes Soto ${ }^{10}$; producto de esta relación nació su hijo Eduardo Obregón Brenes ${ }^{11}$.

El segundo suceso se presentaría el 23 de abril de 1946. Ese día, y pese a que Rafael Obregón no era graduado universitario, se le presentó la oportunidad de ser llamado a trabajar como profesor universitario. Esta situación se debió a que:

Se concedió permiso al Prof. Don Euclides Chacón para retirarse por un año de su cátedra de Geografía.. Para sustituírlo [sic] se presenta la siguiente terna: Rafael Ángel Obregón Loría, Luisa Saborío de Drozd y José F. Garnier. Fue nombrado el Prof. Obregón ${ }^{12}$.

Así, Obregón se integró en 1946 a las cátedras de Geografía e Historia de la Escuela de Filosofía y Letras en la recién fundada Universidad de Costa Rica: ${ }^{13}$

\footnotetext{
${ }^{4}$ Mario Bermúdez, "Adicto al girasol”, Rumbo (14 de abril de 1992), 28.

5 "Rafael Obregón Loría: un estudioso callado y de espíritu joven", La Nación, Sección Áncora (3 de febrero de 1980), 1.

${ }^{6}$ Entrevista efectuada a Raúl Aguilar Piedra, Director General del Museo Histórico Cultural Juan Santamaría, 22 de mayo del 2009.

${ }^{7}$ Fabio Muñoz Campos, "Rafael Obregón Loría, Historia de un historiador", Contrapunto (16 de marzo de 1980), s. p.

8 "Día histórico: Rafael Obregón Loría", La Nación (15 de setiembre de 1982), 2 B.

${ }^{9}$ Gina Polini. "Pilar de la educación", La Nación (15 de octubre de 1991), 2A.

${ }^{10}$ Archivo Nacional de Costa Rica (en adelante ANCR). Expedientes de matrimonios civiles, Exp. 1209, (1943).

${ }^{11}$ Niní De Mora y María Molina de Lines, Rafael Obregón Loría (S. p. i., s.f.), 5.

${ }^{12}$ Tomado del Archivo del Consejo Universitario, vol. 3. Citado por De Mora, Niní, Molina de Lines, María, Rafael Obregón Loría (S. p. i., s.f.), 7.

13 "La unidad de esta institución que hoy conocemos como Universidad de Costa Rica se reestablece en agosto de 1940 cuando, mediante un Decreto de Ley, el Congreso Constitucional de la República dispone que integren la Universidad de Costa Rica las Escuelas de Derecho, Farmacia, Agricultura, Pedagogía y Bellas
} 
Eran los primeros años de la Universidad -explica- y no había muchas personas; apenas se empezaba a formar gente y no había profesores para dar las clases.

Y como "hacían falta" educadores, se escogieron muchos del Liceo de Costa Rica y del Colegio Superior de Señoritas, "que eran los primeros centros de enseñanza.

Entre los llamados se encontraban don Arturo Agüero, don León Pacheco, don Abelardo Bonilla, don Carlos Monge Alfaro, don Isaac Felipe Azofeifa.

Nos llamaron para empujar la Universidad -dice don Rafael Obregón- y también para afianzarla. Llegamos y nos quedamos. Se pudo consolidar el establecimiento ${ }^{14}$.

En medio de esta nueva oportunidad que se le presentaba a Obregón fue reconocido en $1949^{15}$ "por la Secretaría de Instrucción Pública como "profesor de Estado""16. Dicha acreditación se veía facilitada por cuanto el Estado creó este título para quienes eran llamados a desempeñarse en una cátedra y:

...que había demostrado simplemente interés en una materia, en una disciplina y no tenía títulos, entonces después de cinco años de práctica y de un dictamen del cuerpo de directores de colegios, de una especie de tesis, una tesina que presentaba el interesado, el cuerpo de directores otorgaba el título de profesor de estado, ahí seguían trabajando, estudiando por sí solos, leyendo lo que pudieran, preparándose ellos mismos ${ }^{17}$.

Para 1946, específicamente entre el 26 y el 31 de agosto, se efectuaba el Primer Congreso Universitario de Costa Rica. Éste se concibió como un espacio que se abriría para la discusión y el análisis de aquellas reformas tanto académicas como administrativas que resultasen necesarias en este ámbito educativo. De manera concreta, para ese primer contacto dado en la década del cuarenta, la preocupación residía en lograr la unidad institucional dentro de la diversidad de escuelas que la conformaban; se apuntaba además al debate dado alrededor de la aparición de las humanidades (conocidas en la actualidad como

Artes ya existentes". Rita María Porras León, “Apuntes sobre el I Congreso Universitario”, Oficina de Contraloría, Boletín 1-2002, artículo 2 [citado el 3 de septiembre de 2015]: disponible en http://ocu.ucr.ac.cr/Boletines/2002-Boletin1-2.pdf

14 "Rafael Obregón Loría: un estudioso callado y de espíritu joven”, 1.

${ }^{15}$ Además el $1^{\circ}$ de junio de 1941 Obregón fue nombrado Socio fundador de la Sociedad de Geografía e Historia de Costa Rica. Mata, "Don Rafael Obregón Loría (1911-2000)", Diálogos Revista Electrónica de Historia 2, no. 1 (2001 [citado el 3 de septiembre de 2015]): disponible en http://revistas.ucr.ac.cr/index.php/dialogos/article/view/6310/6012

${ }^{16}$ Mata, "Infatigable maestro", 14A.

17 “Discurso pronunciado por el profesor Rafael Obregón Loría. Sesión especial del Consejo Universitario el día lunes 7 de octubre de 1991". Grethel Mena, Luis Felipe Saravia y María de los Ángeles Solano, "Biobliografía Rafael Obregón Loría 1911-2000” (Facultad de Educación, Escuela de Bibliotecología y Ciencias de la Información, Universidad de Costa Rica, 2001), Anexos. 
Estudios Generales) así como también a la creación de políticas claras para contratar profesores $^{18}$.

Así, en estos años se sentaron las bases de lo que llegaría a ser la reforma universitaria de 1957, dirigida por el entonces Rector Rodrigo Facio Brenes. El Rector se hizo acompañar en esta labor por otras personalidades, entre las cuales despuntaba Obregón Loría, quien "junto a figuras como Carlos Monge Alfaro e Isaac Felipe Azofeifa, es uno de los gestores de la reforma universitaria, que rige a partir de 1957"19.

Dentro de este contexto el profesor tuvo una labor destacada al brindarle un impulso a la investigación y a la enseñanza en los departamentos donde se desempeñaba, es decir, los de Historia y Geografía. De esta manera apoyó su constitución como Escuela en 1973 ${ }^{20}$, al momento que se creaba la Facultad de Ciencias Sociales ${ }^{21}$.

Al respecto la entonces directora de la Escuela de Geografía, María Molina de Lines, repasaba hacia 1980 el papel del profesor Obregón:

Yo recuerdo una frase que no la puedo decir de memoria, pero sí la idea de lo que dijo Rodrigo Facio, de tan grata memoria para todos los universitarios, que dijo: voy a buscar entre la gente más capaz y más buena de la Universidad para ponerlos al frente de las nuevas unidades académicas que se iniciaron con la reforma de 1957, y la persona que don Rodrigo Facio nombró para dirigir el naciente departamento de geografía e historia fue al profesor don Rafael Obregón Loría, y yo recuerdo que él lo aceptó por su amor a la historia de Costa Rica, porque era el hombre que más conocía de verdad nuestra historia, sigue siendo el que más la conoce y porque sabía que con él, el Departamento de Historia iba a dar la talla de una unidad académica que en realidad marcara las pautas en la enseñanza y de la investigación histórica ${ }^{22}$.

El profesor Obregón Loría ocupó otros puestos además del de docente. Él se desempeñó como director del Departamento de Historia y Geografía de la Facultad de Ciencias y Letras de la Universidad de Costa Rica entre 1946 y 1956, nuevamente ocuparía el cargo desde 1969 hasta 1975. Mientras que en el período 1979-1981 fue nombrado como Subdirector de la Escuela de Historia y Geografía de esa misma universidad.

\footnotetext{
${ }^{18}$ Raquel Gólcher, "UCR trata de modernizarse. VI Congreso Universitario", La Nación (14 de mayo del 2002 [citado el 3 de septiembre de 2015]): disponible en http://www.nacion.com/ln ee/2002/mayo/14/pais14.html

${ }^{19}$ Doriam Díaz, “iQué vacío dejó don Rafael!”, La Nación, Sección Viva (29 de abril del 2000), 10 Viva.

${ }^{20}$ Patricia Montero Ríos, "Rafael Obregón. Una luz que se apagó", Semanario Universidad (3 al 9 de mayo del 2000), s. p.

${ }^{21}$ Gustavo Naranjo Chacón, "Rafael Obregón Loría. La historia tal y como la conocemos", Revista Abanico, La Prensa Libre (11 de julio del 2001), 4.

22 "Rafael Obregón: Si conociéramos nuestra historia seríamos mejores ciudadanos", Forja, Suplemento cultural del Semanario Universidad (febrero 1980), 3.
} 
Para este último cargo su nombre fue propuesto por Niní de Mora, quien destacó la labor de Obregón de una manera vehemente y categórica:

Honra y prestigia a la Universidad de Costa Rica con su brillante personalidad de Educador, así como es acreedor meritísimo de la gratitud de profesionales, que de estudiantes que encontraron en él al maestro; siempre dispuesto a brindarles no sólo su saber, sino sus medios todos para el logro de su superación intelectual. Historiador insigne. La Patria agradecida lo ha distinguido ya por sus valiosas obras, y no terminaran los merecidos homenajes a quien tanto le ha rendido, porque es incansable en el trabajo de investigación histórica.

No desaprovechemos el poder tenerlo al frente de esta Unidad Académica, su colaboración en el manejo de la Escuela, será como siempre, magnífica, ya que es la única forma en que don Rafael sabe servir ${ }^{23}$.

Durante su estancia en la Universidad de Costa Rica, el profesor Obregón se destacó por su trato erudito pero afable para con los estudiantes; situación que era constatada al impartir una lección u ofrecer una conferencia, ya que "nunca se limita a la exposición del hecho histórico, sino que profundiza en el ambiente, en las circunstancias que lo rodean, y hasta en la psicología de los personajes que intervinieron" ${ }^{24}$. Así, sus clases eran catalogadas como amenas pues "lo anecdótico y lo analítico formaban parte de los borbollones de sabiduría que el maestro entrega en cada clase" 25 .

A este respecto, Raúl Aguilar consideraba que "don Rafael conocía la vida y milagros de la sociedad josefina y las anécdotas eran abundantes. Anécdotas sobre personas y personajes, y anécdotas también de cómo le había llegado él a los libros"26.

Aunado a lo anterior, a Obregón se le reconoce que propició la llegada de profesores extranjeros al país y la salida de estudiantes al extranjero por medio de becas, todo esto con el fin de promover el cambio ${ }^{27}$. Esta labor sería reconocida décadas después:

Por más de cuarenta años fue el gran inspirador de las tesis de grado de los egresados en los campos de historia y geografía y siempre impulsó para que los estudiantes ampliaran sus horizontes realizando estudios de posgrado en el exterior. En la década del setenta y en virtud de las condiciones favorables en la apertura al exterior de la Universidad de Costa Rica, don Rafael trabajó denodamente en la búsqueda de becas para que los estudiantes más destacados en los campos de la

\footnotetext{
${ }^{23}$ Escuela de Historia, "Acta Sesión 38”, Actas de la Asamblea de Escuela 1978 (Escuela de Historia, Universidad de Costa Rica, 7 de diciembre de 1978), 3.

24 “Día histórico: Rafael Obregón Loría”, La Nación (15 de setiembre de 1982), 2 B.

${ }^{25}$ Guillermo Carvajal, "El Doctorado Honoris Causa para don Rafael Obregón Loría”, Semanario Universidad (14 de junio de 1991), 12.

${ }^{26}$ Entrevista efectuada a Raúl Aguilar Piedra, Director General del Museo Histórico Cultural Juan Santamaría, 22 de mayo del 2009.

${ }^{27}$ Díaz, “¡Qué vacío dejó don Rafael!”, 10 Viva.
} 
historia y la geografía pudieran abrirse nuevos horizontes, sin ninguna preferencia, por ninguna escuela de pensamiento, sus discípulos se repartieron por los mejores centros universitario del mundo, dentro de esa proyección internacional del gran maestro en el campo de la historia y la geografía, no puede dejarse pasar por alto su contribución al movimiento de jóvenes historiadores y geógrafos que hoy han hecho los avances más destacados en la América Central ${ }^{28}$.

Otra faceta de Obregón fue aquella marcada por sus ideas liberales y su vinculación masónica. Su filiación lo condujo a ser diez veces Gran Maestro de la Gran Logia Masónica. Asimismo, fue formador y conservador del Museo Masónico que se encuentra en la Gran Logia de San José ${ }^{29}$. Incluso, su aporte al museo fue de tal envergadura que, “precisamente la Logia Masónica lo bautizó como Museo Masónico Rafael Obregón Loría, en honor a don Rafael" $"$.

\footnotetext{
28 “Discurso pronunciado por el Director de la Escuela de Historia y Geografía en Sesión del Consejo Universitario con ocasión de la entrega del Doctorado Honoris Causa al profesor Rafael Obregón Loría". Mena, Saravia y Solano, "Bio-bliografía Rafael Obregón Loría 1911-2000".

${ }^{29}$ Kryssia Ortega y Paola Ramírez, "Historia de luto", La República (26 de abril del 2000), 2 A.

${ }^{30}$ Entrevista efectuada a Raúl Aguilar Piedra.
} 
Imagen 5

Rafael Obregón Loría, masón grado 33

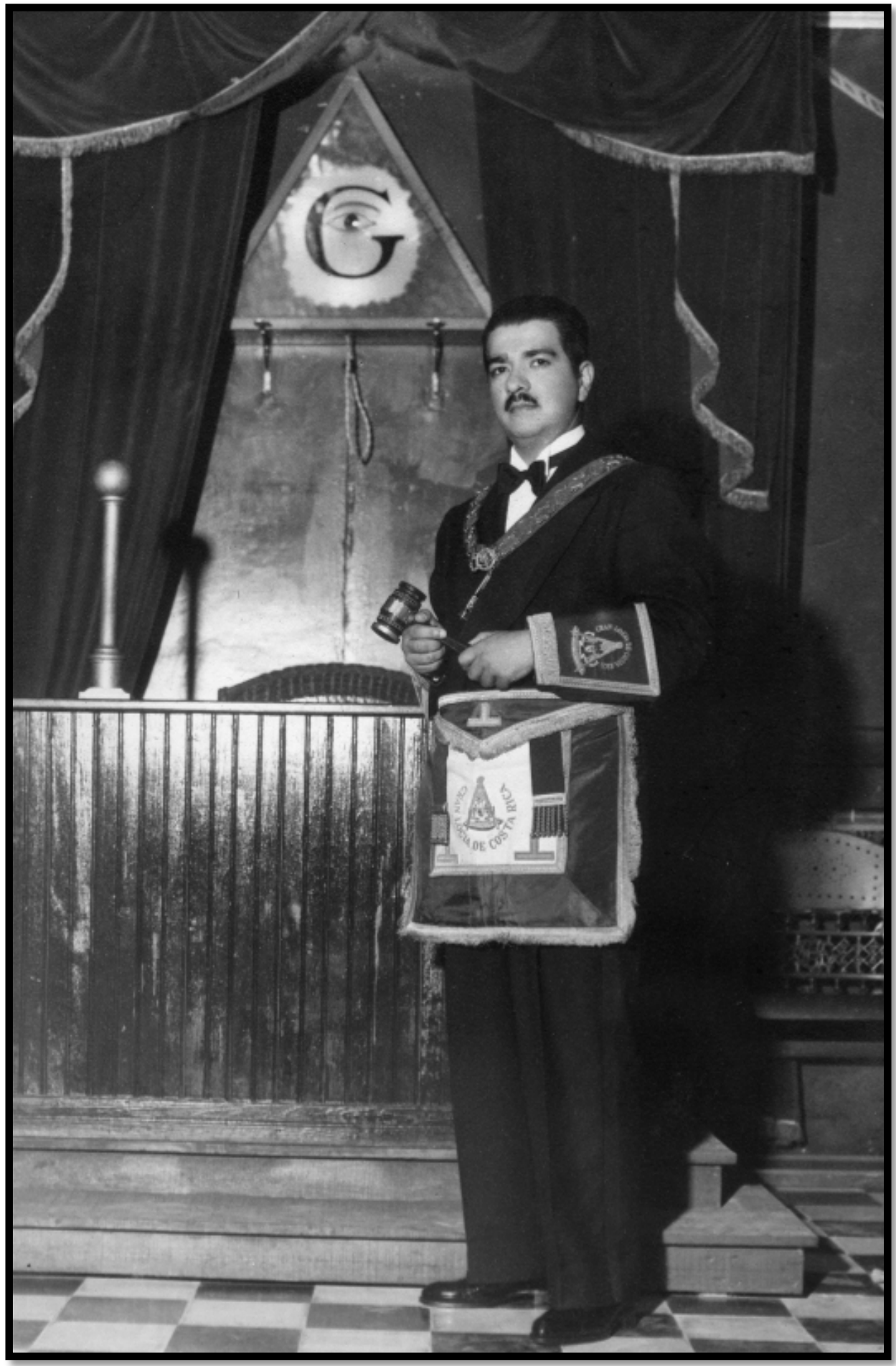

Fuente: Museo de la Gran Logia de Costa Rica. 
De igual manera, el profesor tuvo un papel destacado dentro del Museo Histórico Cultural Juan Santamaría ${ }^{31}$. Esta institución instalada en Alajuela recibió un importante soporte de parte de Obregón:

Don Rafael Obregón, junto con don Carlos Meléndez, podemos considerarlos como las dos columnas sobre las que se levantó el Museo Juan Santamaría desde el punto de vista académico-histórico... prestaron una colaboración al museo, siempre estuvieron atentos a las consultas que nosotros le hacíamos y sobre todo a facilitarnos los recursos que ellos tenían, las bibliotecas.

En el caso concreto de don Rafael, él nos dio posibilidades para la publicación de libros, él estuvo atento. El primer libro que el Museo publicó como libro fue un obsequio de don Rafael nunca antes conversado, sino que un día de tantos me lo entregó en una bolsa de polietileno y me dijo: "Raúl, esta es mi colaboración para el Museo Juan Santamaría. Usted sabe si lo publica, si lo hace coedición o si vende los derechos..." Era una edición revisada de los Conflictos militares y políticos...el libro salió con el nombre de Nuestra historia patria. Hechos militares y políticos. ${ }^{32}$

Además de su contribución como investigador, Obregón suministró información bibliográfica, documentación histórica y estuvo atento y dispuesto a colaborar con dicho ente. De hecho, la institución posee una colección de fotografías (localizadas en el archivo fotográfico del Museo) que han sido reproducidas en varios libros.

Sin lugar a dudas la vida de profesor Obregón estuvo marcada por la educación, a esta labor dedicó casi medio siglo: "Mi vida es la educación. Para mí fue duro el retiro, tuve que efectuarlo en 1981, a los 70 años, porque así lo establece el estatuto orgánico universitario. Me agrada enseñar, es lo que me gusta, lo que siempre hice, ${ }^{, 33}$.

En reconocimiento a esta ardua labor la Universidad de Costa Rica tomó la decisión de denominar su archivo institucional como Archivo Universitario Rafael Obregón Loría. Asimismo, nombró al docente como profesor emérito al tiempo que este continuaba dictando charlas sobre distintos temas ${ }^{34}$.

\footnotetext{
31 "El Museo Histórico Cultural Juan Santamaría fue creado mediante Ley de la República No. 5619, del 4 de diciembre de 1974, reformada por la Ley No. 6572 del 23 de abril de 1981. El proyecto que dio origen a esta ley fue iniciativa del entonces diputado alajuelense Dr. Luis A. Salas Corrales. El Museo lleva el nombre de "Juan Santamaría" en honor al Héroe Nacional, cuya gesta heroica se concreta el 11 de abril de 1856 en Rivas, Nicaragua. El 9 de abril de 1980, el Museo abre sus puertas a la comunidad local y nacional. Este museo es el único en el país especializado en el tema de la Campaña Nacional de 1856-57 contra el invasor filibustero". [citado el 3 de septiembre de 2015]: disponible en http://www.museojuansantamaria.go.cr/Informacion\%20General\%20sobre\%20el\%20Museo\%20Juan\%20San tamaria/index.html\#HERMES TABS 10

${ }_{32}$ Entrevista efectuada a Raúl Aguilar Piedra.

${ }_{33}^{33}$ Mario Bermúdez, "Adicto al girasol", Rumbo (14 de abril de 1992), 28.

${ }^{34}$ Bermúdez. "Adicto al girasol, 30.
} 


\section{Imagen 6}

Entrega del libro Hechos militares y políticos en Costa Rica por parte de su autor, Rafael Obregón, al Lic. Rodrigo Carazo Odio el día 24 de abril de 1980.

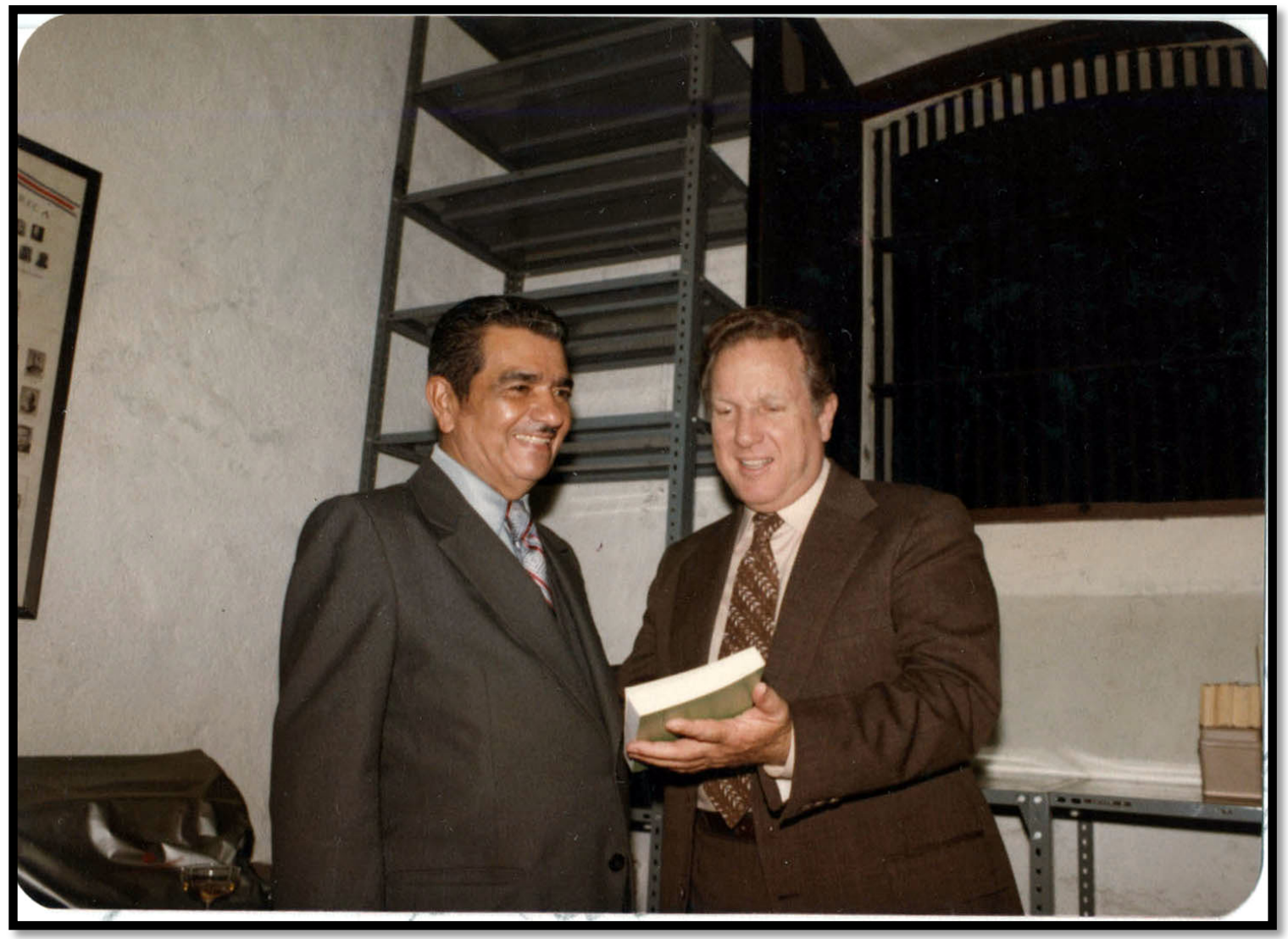

Fuente: Museo Histórico Cultural Juan Santamaría.

Incluso, ya pensionado, Obregón proseguía con su trabajo de investigador, tal y como lo mencionó el Director de Museo Juan Santamaría: “ya en su época tardía, en sus últimos momentos, el Archivo volvió a obtener los servicios de don Rafael y pidió un trabajo interesante sobre don Próspero Fernández, que por lo demás, las historias de don Rafael sobre don Próspero fueron muy interesantes",35.

Al respecto, en una entrevista que sobre estas cuestiones le fue efectuada a Obregón en 1992, el profesor afirmaba:

En estos momentos estoy escribiendo un estudio sobre Próspero Fernández -qué presidente, qué hombre más impresionante- ya entregué la primera parte, biografía y datos familiares, y empezaré a trabajar en la segunda, sobre su obra. También quiero realizar un trabajo sobre historia contemporánea de Costa Rica, de la independencia hasta nuestros días. Los textos y la materia de esta época es algo que

\footnotetext{
${ }^{35}$ Entrevista efectuada a Raúl Aguilar Piedra.
} 
se está perdiendo en la enseñanza, yo tengo resúmenes y quiero dejar algo que se pueda utilizar como texto ${ }^{36}$.

\section{Imagen 7}

Entrega oficial de la colección de las Genealogías Familias alajuelenses por parte del Dr. Luis

Fernando Sibaja y el Dr. Arnoldo Mora a su autor Rafael Obregón.

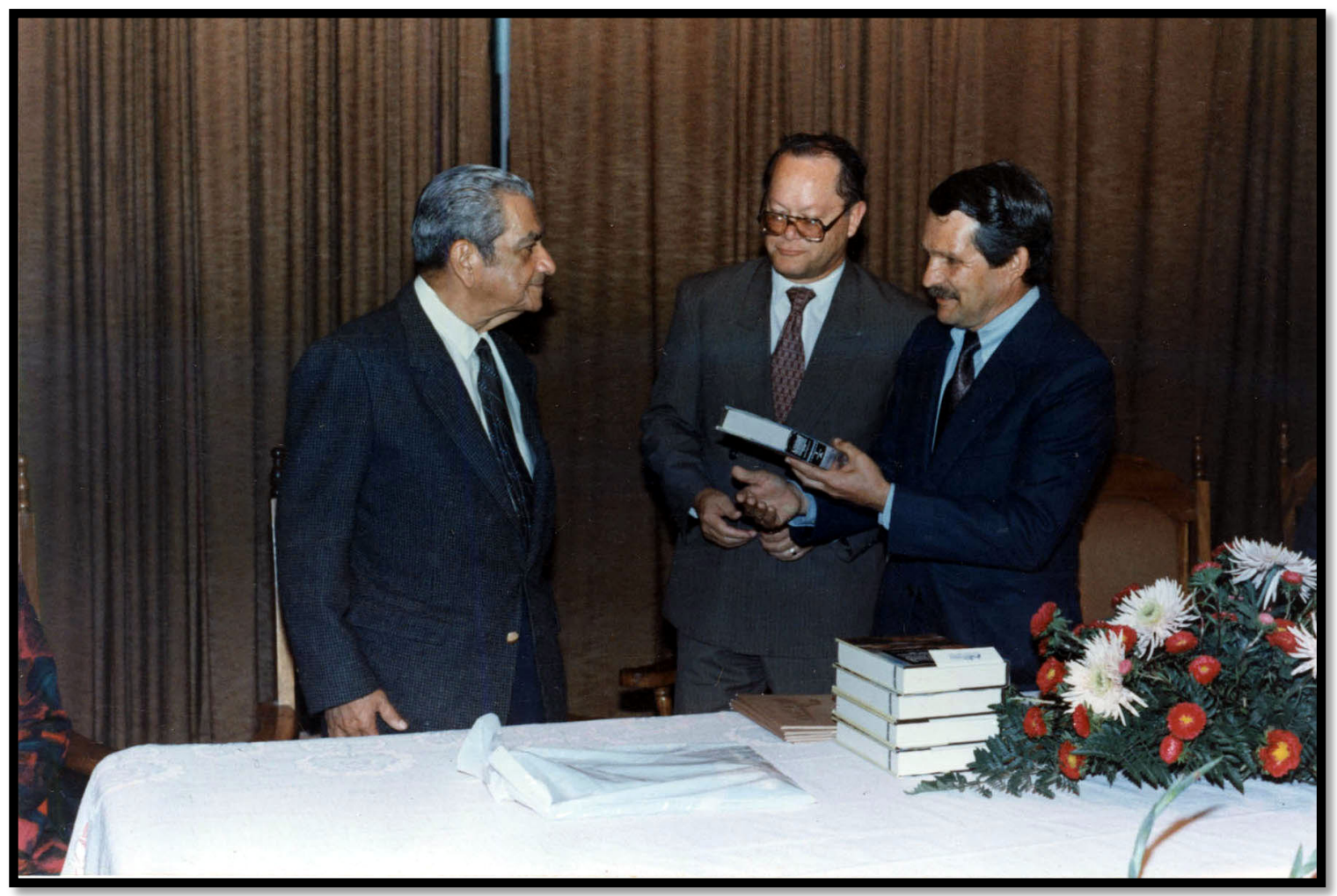

Fuente: Museo Histórico Cultural Juan Santamaría.

A lo largo de estos años el profesor Obregón no sólo destinó su tiempo a la instrucción sobre temas históricos, sino que la investigación ocupó también un lugar relevante en vida profesional, tanto así que desde 1955 se le ve trabajar como investigador de tiempo completo y sus primeros estudios se publican desde una época tan temprana como el año de $1937^{\prime 3}$.

Se comprende entonces el por qué de su prolífica producción historiográfica, misma que versa sobre tópicos que van desde la masonería, la historia patria, la educación, los estudios histórico-militares y los personajes nacionales ${ }^{38}$, hasta la genealogía ${ }^{39}$.

\footnotetext{
${ }^{36}$ Bermúdez. "Adicto al girasol, 30.

37 "Rafael Obregón Loría: un estudioso callado y de espíritu joven, 1.

${ }^{38}$ A este respecto, es importante acotar que dos personas que llamaron profundamente la atención de Obregón Loría fueron Braulio Carrillo y José María Castro Madriz. "Rafael Obregón: Si conociéramos nuestra historia seríamos mejores ciudadanos”, 4.
} 
La "pluma pródiga" 40 del profesor Obregón dejó de trazar las líneas de la Historia al morir el 25 de abril del 2000. A partir de entonces se verificaron en su honor distintas muestras de recordación. Una de ellas se efectuó en la Asamblea Legislativa. En esta institución se recordó su fecunda labor y con ella el aporte que le brindó a las artes, la cultura y la educación del país; posteriormente se guardaría un minuto de silencio por el "maestro e historiador"

Paralelamente se reafirmaba en los periódicos, en la academia y en las distintas instituciones, así como entre sus colegas y amigos el vacío que implicaba la desaparición de "nuestro historiador del siglo XX"42.

Ha muerto el insigne maestro de la historia de Costa Rica, el patriota sincero, el maestro de generaciones, el escritor pulcro y ameno, el ciudadano sin tacha, pero su figura seguirá creciendo con los años, porque hombres como él son los imprescindibles ${ }^{43}$.

\section{La renovación historiográfica y sus intereses disciplinarios}

Sin lugar a dudas, el establecimiento hacia la década de los años cuarenta del siglo XX de la Universidad de Costa Rica, constituyó un elemento determinante en el impulso que experimentaron las Ciencias Sociales en general y los estudios humanísticos en particular, como ya se ha venido anotando.

La disciplina histórica no fue ajena a estas transformaciones gestadas desde el campus mismo. En ella, figuras de la talla de Carlos Monge Alfaro, Carlos Meléndez Chaverri y Rafael Obregón Loría convergieron positivamente en la promoción de un conjunto de esfuerzos tendientes a superar la concepción de Historia que prevalecía hasta entonces; a saber, un conocimiento del pasado desarticulado, sin rigor científico, con un enfoque donde predominaba la especulación y el subjetivismo, así como la ausencia regular de fuentes citadas que ofrecieran una perspectiva clara del origen de la información que se utilizaba.

\footnotetext{
${ }^{39}$ Naranjo Chacón, "Rafael Obregón Loría. La historia tal y como la conocemos, 4. Mata, "Infatigable maestro", 14A.

${ }^{40}$ Carvajal. "El Doctorado Honoris Causa para don Rafael Obregón Loría”, 12.

41 "Actualidad legislativa" (25 de abril del 2000 [citado el 3 de septiembre de 2015]): disponible en http://www.asamblea.go.cr/actual/boletin/2000/abr00/25abr00.htm

${ }^{42}$ Díaz, "¡Qué vacío dejó don Rafael”, 10. Mora, "Historia patria de luto. Murió Rafael Obregón Loría”, 2.

${ }^{43}$ Arnoldo Mora Rodríguez, "La muerte de Rafael Obregón”, La República (5 de mayo del 2000), 11A.
} 
Imagen 8

Rafael Obregón Loría y Carlos Meléndez Chaverri, s.f.

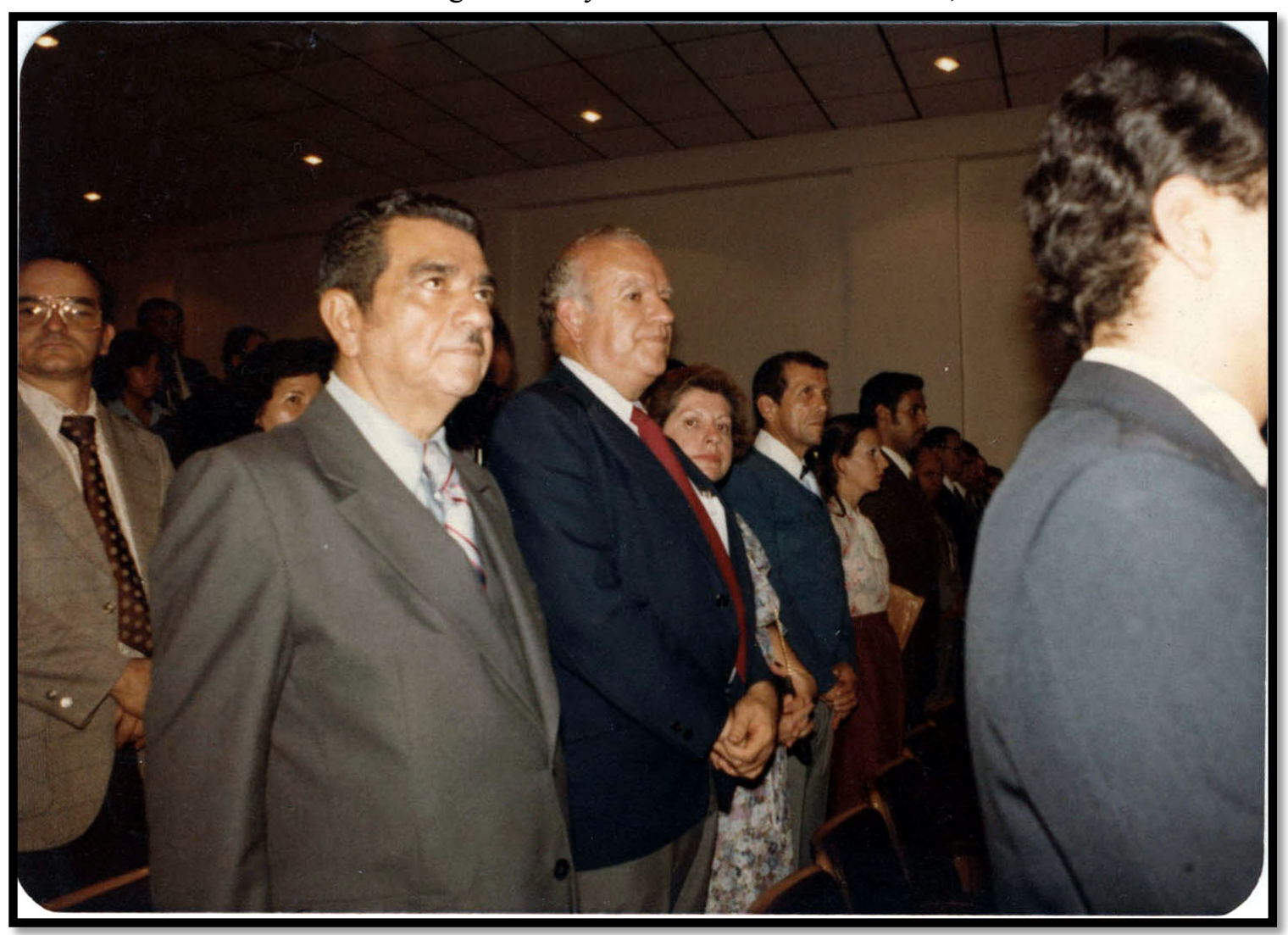

Fuente: Museo Histórico Cultural Juan Santamaría.

De entre estos historiadores quien destacó por el sentido humanista de los estudios que llevó a cabo, fue sin duda Rafael Obregón Loría. Si bien es cierto el grueso de su producción historiográfica estuvo circunscrita al prolífico siglo XIX, también lo es que dentro de esta rica centuria abordó multiplicidad de temas. Algunos de ellos nunca antes abordados en el país, otros analizados desde nuevas perspectivas, con enfoques novedosos. Su impresionante producción es un testimonio fiel, no sólo de la acuciosidad con la que asumía su trabajo, sino de la vocación natural que le caracterizó por la difusión del conocimiento histórico entre la población costarricense.

Rafael Obregón no fue un historiador centroamericanista, en verdad. Con todo y que no carece de algunos estudios de carácter regional, sus intereses privilegiaron el análisis del pasado costarricense: de sus personajes y de los grandes acontecimientos que marcaron el rumbo del país. Se constituyó en un claro precursor de las discusiones disciplinarias contemporáneas sobre el tema de la construcción de la nacionalidad costarricense y al igual que el grueso de los historiadores locales de ayer y hoy, fue el estudio del pasado costarricense su gran pasión. 
Aunado a lo anterior, destaca Rafael Obregón por haber propiciado la llegada al país de los historiadores suramericanos como Ciro Cardoso y Héctor Pérez, figuras esenciales que promovieron una renovación de los estudios históricos en Costa Rica ,"todo con el fin de promover el cambio" 44 .

De entre su extensa producción historiográfica destacan algunos ejes de interés, que procuraremos enmarcar como esenciales dentro de las preocupaciones que movieron la obra de Obregón Loría. Sin que esta propuesta pretenda constituir un perfil definitivo en esa dirección, busca ante todo establecer criterios de clasificación, antojadizos en todo caso, en tanto, es sabido que quien lleva a cabo la labor de producción de conocimiento a lo largo de su vida, se mueve por motivaciones de distinta naturaleza y no organiza su obra derivada de razones sistemáticas o considerando criterios de orden cronológico; simplemente quien investiga se ve imbuido, como cualquier mortal, en múltiples preocupaciones académicas que tarde o temprano traduce en trabajos que dejan de ser suyos y se convierten en conocimiento compartido del que se apropian, quienes al igual que el historiador, guardan esa pasión por escudriñar y conocer mejor su pasado.

\section{EI siglo XIX}

Citando al reconocido investigador francés, Jules Michelet que afirmaba que conociendo bien la patria, se le ama mucho más, Rafael Obregón siempre sostuvo que tal postulado era una gran verdad, en tanto conocer al país, su tierra, sus montañas y sus llanuras, provocan que se le adore más, "por eso me atraen la historia y la geografía: nos permiten querer más a Costa Rica" $"$. En efecto, su amor por la patria lo llevó a realizar múltiples estudios sobre los temas más diversos de nuestro pasado.

Se consideraba a si mismo autodidacta y no fueron pocas las veces en las que las lecturas, ausentes de mediación pedagógica como se diría hoy en día, sustituían las jornadas académicas del aprendizaje disciplinario. “Obregón es uno de los máximos representantes de una generación de educadores que difícilmente se repetirá, humanistas de talla universal" 46 y tuvo la virtud de hacer florecer la Academia Universitaria con humanistas como Rodrigo Facio Brenes, Abelardo Bonilla e Isaac Felipe Azofeifa, entre otros.

Sin embargo, lo suyo, su interés primordial, siempre giró en torno a la historia del siglo XIX costarricense. "He puesto mi interés sobre todo en el siglo XIX, esa es mi especialidad. Todo mi trabajo se refiere a esa época"47, confesaba en 1980 . Y es que en verdad, la revisión de la producción historiográfica de Rafael Obregón revela un exhaustivo interés por esta centuria, por sus figuras destacadas, especialmente por algunos de sus Jefes de Estado y Presidentes. "Estoy encariñado con este siglo y admiro profundamente a sus

\footnotetext{
${ }^{44}$ Díaz, “¿Qué vacío dejó don Rafael!”, 10 Viva.

${ }^{45}$ Bermúdez, "Adicto al girasol", 28.

${ }^{46}$ Bermúdez, "Adicto al girasol”, 28.

${ }^{47}$ Muñoz Campos, "Rafael Obregón Loría, Historia de un historiador".
} 
personajes. En el caso de Costa Rica admiro al Dr. Castro Madríz, a Braulio Carrillo, Juan Rafael Mora, Tomás Guardia. Son personas que difícilmente se presentan en este siglo que estamos viviendo" ${ }^{, 48}$, expresaba Obregón Loría hacia finales del siglo XX.

En efecto, algunos de gobernantes fueron objeto de estudios meticulosos por parte del notable historiador. Llevó a cabo dos investigaciones sobre los gobiernos de José María Castro Madriz, por quien sentía una profunda admiración dada su inclinación al respecto a las voluntades ajenas y a su vocación liberal. Tanto fue así que a pesar que el gobernante cayó dos veces del poder resultado directo de golpes de Estado, no fue un personaje desestabilizador del orden público.

Son también conocidos sus trabajos sobre algunos hombres enérgicos y visionarios del siglo XIX, que habiendo ocupado el máximo poder del país, impulsaron cambios significativos en distintas áreas. Destacan sus trabajos sobre Braulio Carrillo Colina, el llamado "Arquitecto del Estado costarricense" y sobre Tomás Guardia, militar que acabó de forma progresiva con el fenómeno del "golpismo" durante el último tercio del siglo XIX. No menos conocidos son sus estudios vinculados con los rectores de la Universidad de Santo Tomás, con su padre Miguel Obregón Lizano y sobre períodos claves de la historia costarricense de entonces, en particular, sobresalen sus trabajos relacionados con los primeros días de la independencia, la participación en la Federación Centroamericana, el poder legislativo y nuestras relaciones internacionales a mediados del siglo $\mathrm{XIX}^{49}$.

Es posible encontrar en la obra de Rafael Obregón algunos trabajos menores sobre la colonia costarricense, como por ejemplo, "Los gobernantes de la Colonia" y "Movimientos antiespañoles en Centroamérica", sin embargo, al igual que ocurre con algunas de sus obras que trabajan aspectos puntuales del siglo $\mathrm{XX}$, ambos casos constituyen, más bien una excepción, ante el interés primordial que el historiador tuvo sobre acontecimientos y personajes del siglo XIX a lo largo de su obra historiográfica.

\section{La Campaña Nacional (1856-1857)}

Dentro de los estudios que Rafael Obregón llevó a cabo y que se encuentran circunscritos al siglo XIX, aquellos relacionados con la Campaña Nacional y la lucha ejecutada contra los filibusteros encabezados por William Walker, guardan especial importancia. En palabras del historiador es en estos temas donde obtuvo su mayor satisfacción. "Considero que mi mejor obra es La Guerra de 1856, que en principio fue titulada Guerra de Tránsito. Es un libro apasionante, por el tema, y porque en realidad contiene mucha bibliografía enfocada desde muchos puntos de vista"50.

\footnotetext{
${ }^{48}$ Muñoz Campos, "Rafael Obregón Loría, Historia de un historiador".

${ }^{49} \mathrm{Al}$ respecto véanse los anexos del presente trabajo sobre parte de la producción de Rafael Obregón Loría a lo largo de su fructífera carrera como historiador.

${ }^{50}$ Muñoz Campos, "Rafael Obregón Loría, Historia de un historiador".
} 
La obra evidencia una preocupación esencial desde el punto de vista disciplinario en ofrecer una visión del pasado que preserve la mayor fidelidad de los acontecimientos ocurridos. De igual forma, se presenta un interés manifiesto por investigar la posición costarricense y la actitud mostrada por los miembros del ejército durante la guerra contra los filibusteros. En otras voces, la obra La Campaña de Tránsito, constituye la investigación más destacada de Rafael Obregón, puesto que es una obra "pionera que aporta elementos de análisis necesarios para comprender tan importante gesta histórica, a la vez que sitúa la Campaña contra los filibusteros en el ámbito internacional en que se desarrolló, ${ }^{\prime 51}$.

Obregón Loría es considerado el historiador por excelencia de la Campaña Nacional. Sus trabajos son pioneros en el tratamiento de la información y en el enfoque que brinda. A diferencia de los trabajos que le anteceden y que abordan el tema de la guerra contra los filibusteros, las investigaciones que lleva a cabo se caracterizan por un esfuerzo notable encaminado a ofrecer interpretaciones de los acontecimientos y sus protagonistas, así como un interés por el estudio de las fuentes asociadas a las distintas batallas vinculadas con el conflicto armado.

Obregón Loría es enfático en señalar la importancia que la Campaña Nacional tuvo en la configuración de la identidad costarricense y en este particular se adelantó a las fértiles discusiones teóricas que hacia fines del siglo anterior y principios de éste, se llevaron a cabo entre historiadores costarricenses y centroamericanos. En sus palabras expresó el tema en los siguientes términos: "Considero que la Guerra de 1856 fue la época más importante para nuestro país. A partir de ese momento se formó parte de nuestra nacionalidad y reafirmamos en mucho nuestra independencia" ${ }^{52}$. Dicho de otra forma, la guerra ejecutada contra los filibusteros hacia mediados del siglo XIX representa los rasgos característicos de una guerra anticolonial, como en efecto fue.

\footnotetext{
51 "Doctor Honoris Causa UCR: Rafael Obregón Loría". Muñoz Campos. "Rafael Obregón Loría, Historia de un historiador".
} 


\section{Imagen 9}

Clotilde Obregón Quesada y Rafael Obregón Loría en la ceremonia de entrega del libro Costa Rica y la guerra contra los filibusteros, efectuada en el auditorio del Museo Histórico Cultural Juan Santamaría, el 17 de diciembre de 1991.

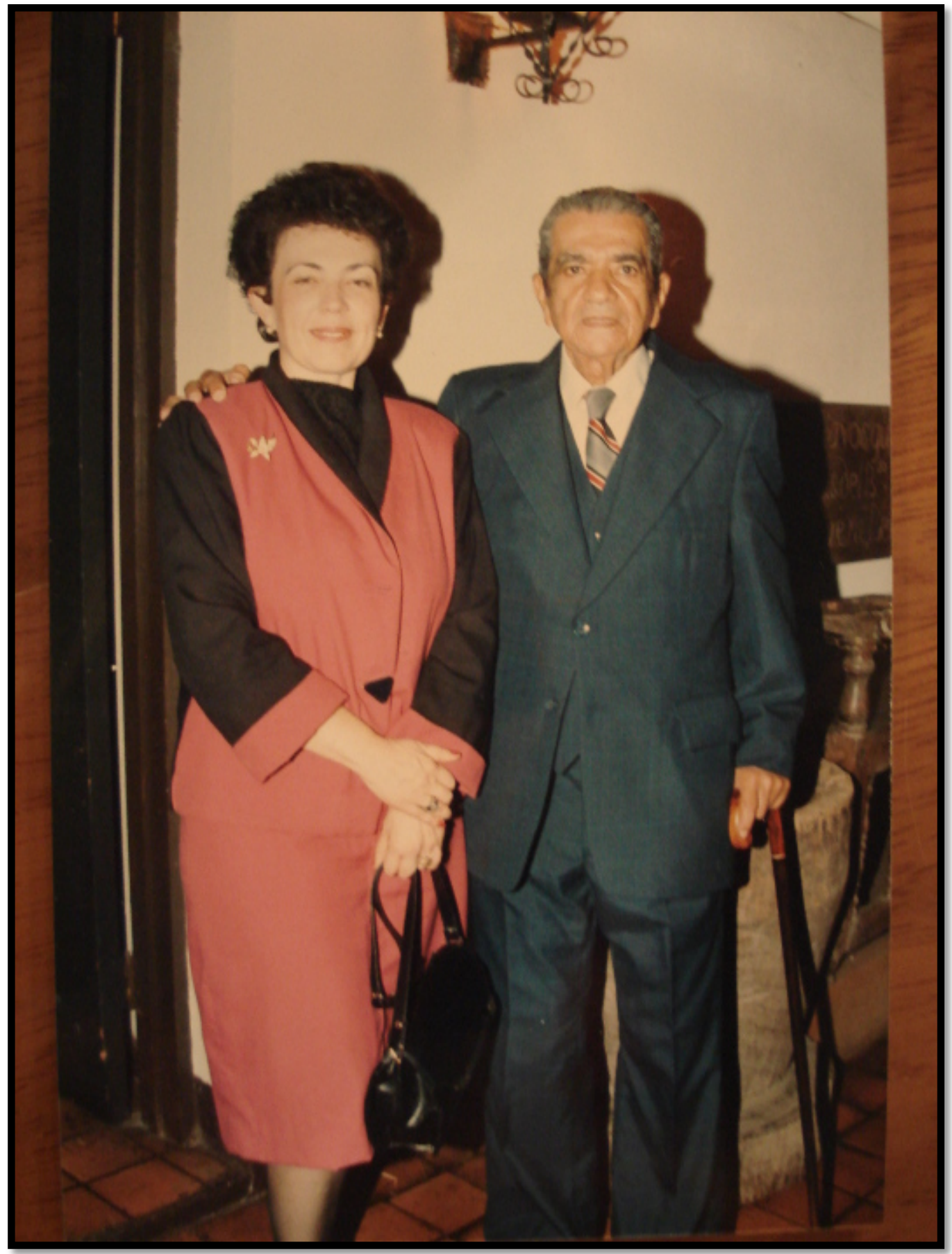

Fuente: Museo Histórico Cultural Juan Santamaría. 
Rafael Obregón vive una época particularmente intensa relacionada con la Campaña Nacional y es el llamado Centenario de la Guerra contra los filibusteros. Esta conmemoración de carácter coyuntural resultó un estímulo que favoreció la aparición de un conjunto de estudios asociados con la guerra en su conjunto y con algunos personajes protagonistas de la misma en particular. No es de extrañar que ciertos estudios asociados con la figura del héroe Juan Santamaría, inmolado en la no menos célebre Batalla del 11 de Abril de 1856, surgieran también en el período asociado con las celebraciones del centenario, llevadas a cabo hacia mediados del siglo XX.

Situación similar ocurrió en la década de los años veinte del siglo $\mathrm{XX}$, cuando en concordancia con las conmemoraciones asociadas con el centenario del natalicio del héroe alajuelense ya citado, tanto la Municipalidad de Alajuela como las autoridades estatales del momento, implementaron medidas para promover el desarrollo de investigaciones relacionadas con la Batalla del 11 de Abril y con el impacto que la misma provocó entre la ciudadanía costarricense de la segunda mitad del siglo XIX ${ }^{53}$.

Derivado de su interés meticuloso para estudiar la Campaña Nacional resultan obras como "La Campaña de Tránsito", "Doña Manuela Santamaría”, un interesante trabajo sobre la naturaleza de los polémicos apellidos de la madre del héroe nacional, "Costa Rica y la Guerra del 56", un estudio reeditado y derivado de su obra "La Campaña de Tránsito" y finalmente, "Costa Rica y la Guerra contra los Filibusteros", publicada en el año 1991.

Ningún otro historiador ha resultado tan prolijo en llevar a cabo estudios tan profundos y amplios sobre cuestiones esenciales del mayor y más importante conflicto vivido por Costa Rica en su pasado. Quizá, en ese sentido, merezca mencionarse que un historiador contemporáneo a Rafael Obregón abordó algunos aspectos de la Campaña, en menor extensión y rigor, a decir verdad, como fue Carlos Meléndez Chaverri. De éste en particular, resulta indispensable mencionar su trabajo titulado "Luis Pacheco Bertora: un héroe olvidado", estudio relacionado sobre un soldado cartaginés de notable participación en la Batalla del 11 de abril. Igual, es destacable su texto "La Batalla de Santa Rosa", que versa sobre el combate efectuado en la zona actual de Liberia, denominada Moracia a fines de la década de los años cincuenta del siglo XIX, en el que fueron derrotados los filibusteros que habían penetrado territorio costarricense en marzo de 1856. Y finalmente, sobresale su más elaborado trabajo sobre algún tema relacionado con la Campaña Nacional, como fue "Juan Santamaría: una aproximación al estudio del héroe" "54. Este texto constituye un primer esfuerzo por tratar de comprender las fuentes históricas asociadas con el pasado del héroe costarricense caído en combate.

\footnotetext{
${ }^{53}$ Véase, por ejemplo, el libro recopilatorio de Luis Dobles Segreda titulado "El Libro del Héroe", del año 1926, que recoge múltiples evidencias (poemas, comentarios, artículos, etc.), sobre la participación de Juan Santamaría en la batalla mencionada.

${ }^{54}$ Publicado por el Museo Histórico Cultural Juan Santamaría en el año de 1981.
} 
Como se podrá apreciar, Rafael Obregón Loría representa, con todo mérito, el mejor exponente de la historiografía costarricense, en las investigaciones llevadas a cabo sobre aspectos medulares asociados con la guerra contra los filibusteros.

\section{La masonería como objeto de estudio}

El área de la masonería es un asunto relacionado en dos direcciones con Rafael Obregón Loría; en primer lugar, ligado de forma íntima a su vida, con cerca de 40 años de militancia y en segunda instancia, como profuso investigador del tema citado. Obregón fue Gran Maestro de la Gran Logia de Costa Rica, seis veces Venerable Maestro de la Logia Hermes Número 7 y fundó en esa institución el museo que en la actualidad lleva su nombre en la capital costarricense, como ya se anotó líneas atrás ${ }^{55}$.

La práctica de la masonería tiene vínculo con el liberalismo que siempre profesó Rafael Obregón. "Escogí la masonería por encontrar en ella precisamente las ideas liberales. Vi en ella a la institución que había luchado por la defensa de la libertad en diferentes pueblos, vi que estaba sustentada por hombres ilustres" ${ }^{\text {", }}$, es decir, la masonería representó un punto de encuentro de ideales compartidos. La masonería, desde su punto de vista, ha encontrado campo para desarrollarse en asociaciones filantrópicas que trabajan por el mejoramiento de sus miembros, desde el punto de vista intelectual y espiritual.

Sin embargo, la masonería no ha sido un asunto en la historia de Costa Rica de mera filantropía. Según la obra de Obregón Loría, en el siglo XIX:

... como las masonerías estaban constituidas por elementos de mucha influencia política, lograron cristalizar sus ideas y muchas leyes liberales en el país, por ejemplo, la ley de la secularización de los cementerios y las leyes de la enseñanza. El Código Civil es producto de una disposición del Gobierno de Próspero Fernández. La Comisión que estudió ese código estuvo integrada por masones como Bernardo Soto, Francisco Chávez Castro y Asunción Esquivel. Otras leyes novedosas como el matrimonio civil y el divorcio que se juzgaron en la época como medidas liberales, son conquistas de los masones ${ }^{57}$.

Su interés por la práctica de la masonería en Costa Rica, lo llevó inevitablemente al estudio del tema mismo. Es reconocido como el principal estudioso que de la masonería en el país. Entre sus estudios destacan: "El presbítero y Dr. Francisco Calvo, organizador de la masonería en Costa Rica", "La Masonería en Costa Rica", investigación constituida por

\footnotetext{
${ }^{55}$ Vladimir de la Cruz de Lemos, "R $\therefore$ H $\therefore \backslash$ Rafael Obregón Loría, Benemérito de la Masonería Costarricense, en el centenario de su natalicio”, Revista Estudios 25, no. 1 (2012 [citado el 15 de octubre 2015]): disponible en http://revistas.ucr.ac.cr/index.php/estudios/article/view/2721/2670

${ }^{56}$ Muñoz Campos. "Rafael Obregón Loría, Historia de un historiador".

${ }^{57}$ Muñoz Campos. "Rafael Obregón Loría, Historia de un historiador".
} 
cuatro tomos publicados entre 1937 y 1950 en colaboración con George F. A. Borden y finalmente, "Actividades masónicas en Centroamérica antes de 1865"

En el tema de la masonería, Rafael Obregón, logró combinar un particular liderazgo como miembro activo de la logia en Costa Rica, a su vez, como investigador profundo del fenómeno masón, no sólo en el país, sino a nivel regional.

\section{Genealogías, artículos y editoriales}

Hacia el final de su vida, Rafael Obregón llevó a cabo un valioso proyecto relacionado con el estudio de las familias originarias de la provincia de Alajuela. Patrocinado por el Museo Histórico Cultural Juan Santamaría, se publicaron, en ese sentido, una serie de tomos ${ }^{59}$. En palabras del historiador alajuelense Iván Molina, "La colección Familias Alajuelenses en los libros parroquiales, del profesor Rafael Obregón Loría, es sin duda el proyecto editorial más ambicioso que ha emprendido el Museo Histórico Cultural Juan Santamaría"60. En efecto, el alcance que ha tenido esta labor de naturaleza genealógica ha resultado significativo desde todo punto de vista.

Imagen 10

Colección Familias alajuelenses en los libros parroquiales, estudio genealógico desarrollado en su etapa final por Rafael Obregón Loría.

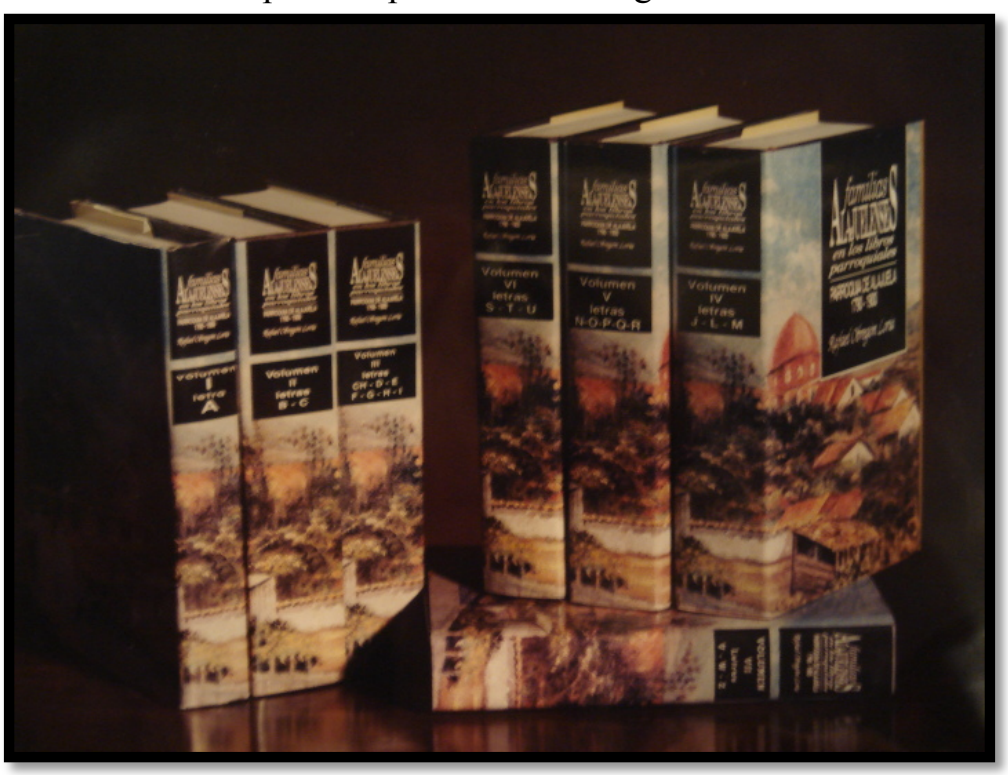

Fuente: Museo Histórico Cultural Juan Santamaría.

\footnotetext{
${ }^{58}$ El libro fue escrito en el año de 1965. En el presente texto incluimos un interesante artículo sobre la masonería publicado por Obregón Loría en la Revista de los Archivos Nacionales.

${ }^{59}$ Rafael Obregón Loría, Familias alajuelenses en los libros parroquiales. Parroquia de Alajuela. 1790-1900 (Alajuela: Museo Histórico Cultural Juan Santamaría, 2003).

${ }^{60}$ Iván Molina Jiménez, "Documentos y genealogías. A propósito de un libro de Rafael Obregón Loría y otro de Carlos Meléndez Chaverri”, Revista del Archivo Nacional LXI, no. 1-2 (1997): 71.
} 
El trabajo de Obregón Loría "es estratégico en el sentido cultural: ofrece a los alajuelenses de fines del siglo XX, un instrumento para recuperar sus identidades personales y familiares y, por esta vía, el pasado de su ciudad y de su sociedad"61. Trabajos en el plano de las genealogías no son frecuentes en nuestro medio y destacar éste en particular resulta necesario, dado lo significativo que ha sido para un conglomerado social representativo de la nación.

\section{Imagen 11}

Ceremonia oficial de entrega del VI Volumen de Genealogías Familias Alajuelenses a su autor. Eduardo Soto Chavarría, Rafael Obregón Loría, Raúl Aguilar Piedra, Luis Fernando Sibaja y

Eduardo Fournier, 25 de junio de 1988.

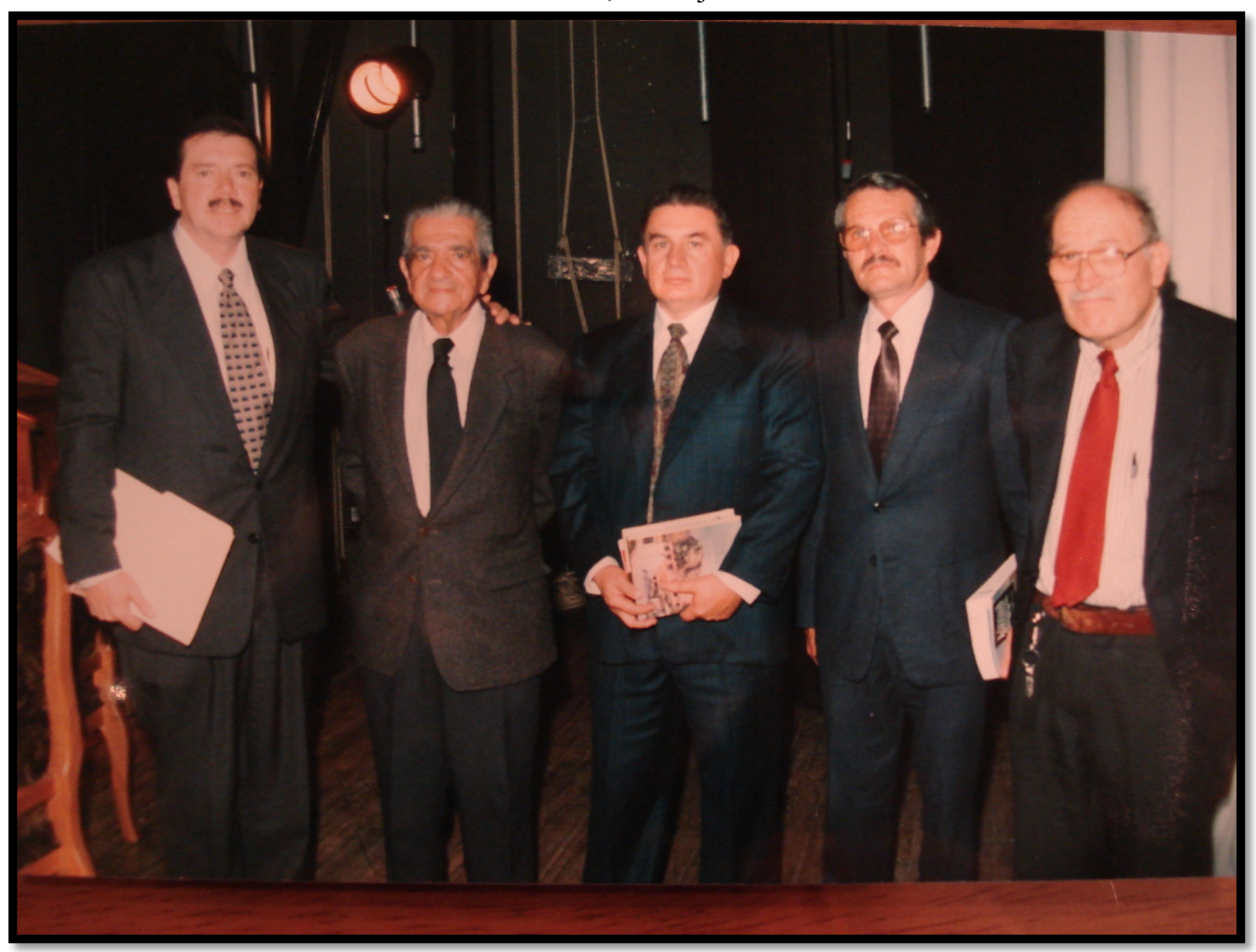

Fuente: Museo Histórico Cultural Juan Santamaría.

Los trabajos de Rafael Obregón fueron publicados por diversas editoriales del país. Su difusión fue masiva y el público beneficiado múltiple. Diversas investigaciones del autor fueron publicadas por el Museo Histórico Cultural Juan Santamaría, institución con la que tuvo colaboraciones hasta el final de su fructífera carrera. De igual forma, destacan sus

\footnotetext{
${ }^{61}$ Molina Jiménez, "Documentos y genealogías”, 71.
} 
trabajos producidos por la Editorial de la Universidad de Costa Rica en diversas etapas de su vida profesional. La Imprenta Nacional publicó también algunas de sus obras. Otras editoriales con las que produjo parte de su obra historiográfica son la Editorial Costa Rica, Imprenta Borrasé e Imprenta Tormo.

Finalmente y no por ello menos importante, es necesario destacar la larga trayectoria de Obregón Loría como colaborador articulista de periódicos nacionales y revistas especializadas. Sus contribuciones son numerosas en periódicos como La República; así como en diversas revistas: Crónica, Brecha, Repertorio Americano, Eureka, Revista del Archivo Nacional y Revista de Filosofía ${ }^{62}$. Sus contribuciones permitieron difundir en un público mayor, ciertas nociones históricas asociadas con diversas formas de percibir el pasado.

\section{Imagen 12}

Entrega oficial del volumen II y III de las Genealogías Familias alajuelenses por parte de Rafael Obregón el 11 de octubre de 1995.

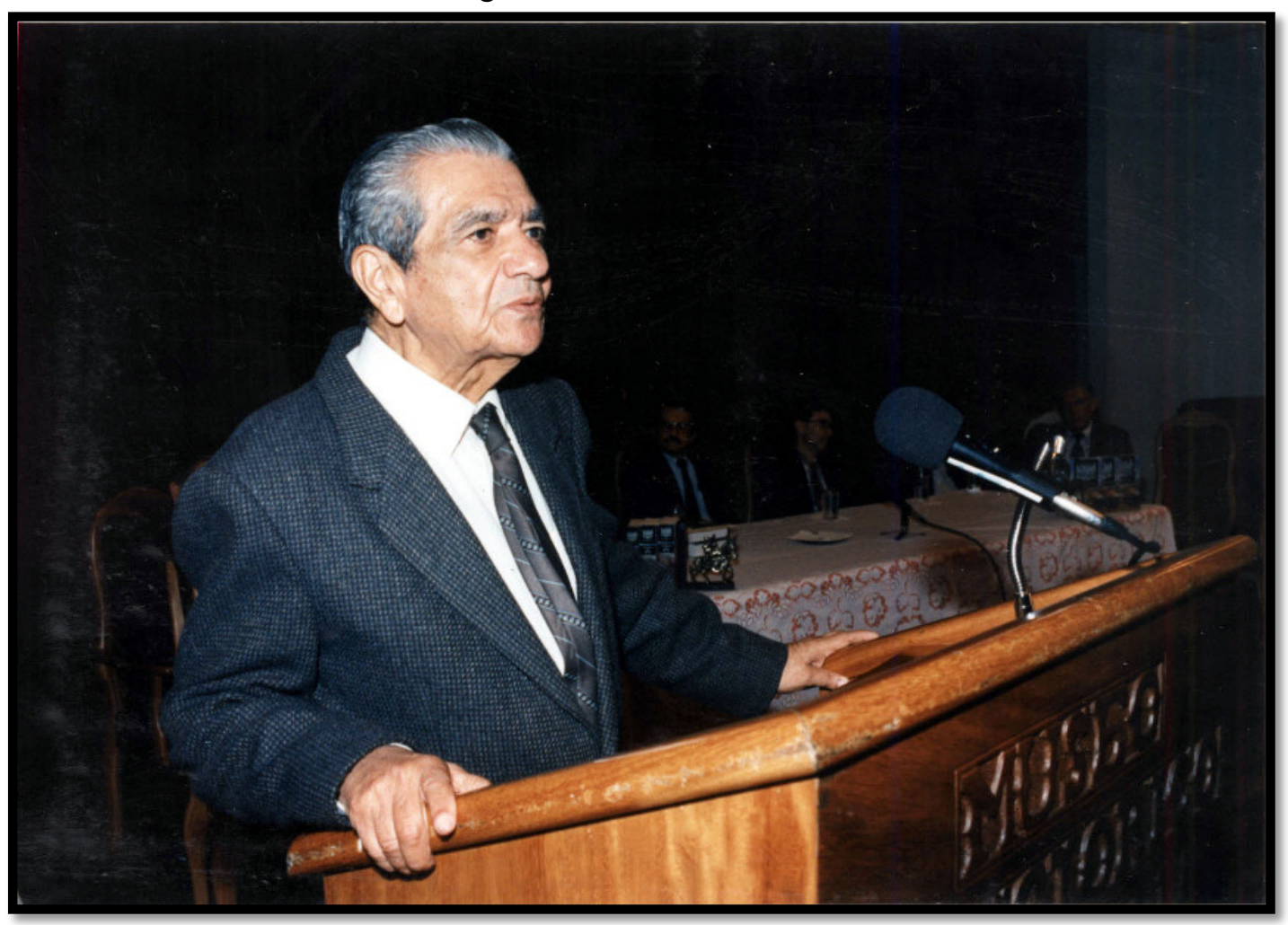

Fuente: Museo Histórico Cultural Juan Santamaría.

\footnotetext{
${ }^{62}$ Es importante anotar, que dentro de su prolija labor historiográfica publicó bajo el seudónimo de Emmanuel Aguilar en el año 1935, la obra llamada "Don Miguel Obregón Lizano. Fundador y organizador de Bibliotecas Públicas". Asimismo, en 1950 dio a conocer el trabajo denominado "Don Miguel Obregón Lizano y el Instituto de Alajuela". Finalmente, bajo el seudónimo de Esteban Iglesias, en 1977, "Crónica de un golpe de Estado". "Doctor Honoris Causa UCR: Rafael Obregón Loría".
} 


\section{Un hombre laureado y sobrio}

El desempeño académico mostrado por el profesor Obregón fue objeto de distintos y reconocidos méritos. Cada uno de estos galardones propugnaba por rescatar no únicamente su labor sino también el aporte que le significaba a la sociedad costarricense.

Uno de los primeros reconocimientos de envergadura nacional concedidos a Obregón Loría fue el Aquileo J. Echeverría en la rama de Historia, esto en 1971. Siendo éste el máximo galardón que el Ministerio de Cultura de Costa Rica entrega año con año como una manera de realzar las obras dadas a conocer en el año inmediato anterior al instante en que fue conferida.

Transcurrirían ocho años más -es decir en 1979- para que el profesor nuevamente fuera honrado; entonces, recibió el Premio Nacional de Cultura Manuel González Zeledón (Premio Magón). Con esta distinción el Gobierno reconocía la "labor de toda una vida" de un ciudadano en el campo de la cultura; a través de él se brindaba un homenaje a una trayectoria emprendedora que "nos mostrará su proceso existencial, su vocación, luchas, experiencias, esfuerzos, sufrimientos, y esencialmente, [sic] la pasión que será la guía hacia la meta escogida"63.

En 1985 nuevamente el nombre de Obregón figuraba entre los condecorados, en ese momento a través del Premio Fernández Ferraz, del Instituto de Cultura Hispánica de Costa Rica (ICI); el cual es otorgado a algún educador costarricense que haya dedicado su vida a la enseñanza superior ${ }^{64}$. Más tarde, en 1997 el Instituto Panamericano de Geografía e Historia (IPGH) le confirió su premio.

En cuanto a los reconocimientos que la Universidad de Costa Rica le concedió se deben destacar entre otros la develación de una placa en su honor en junio de 1973. Ésta se encuentra frente a la Biblioteca Carlos Monge Alfaro y expresa: "Homenaje del Primer Congreso de Estudiantes del Departamento de Historia y Geografía al ilustre historiador, mentor y amigo Profesor Rafael Obregón Loría. Junio 1973 AEHG”.

Asimismo, este historiador fue reconocido en un primer momento como profesor catedrático y posteriormente emérito. Para 1989 se le encomendaría a Obregón la tarea de dictar la lección inaugural del ciclo lectivo en dicha casa de estudios superiores.

\footnotetext{
${ }^{63}$ Amalia Chaverri, "Magón en el panorama cultural costarricense", Ministerio de Cultura y Juventud (18 de julio de 2014 [citado el 3 de septiembre de 2015]): disponible en http://www.mcj.go.cr/convocatorias premios/magon/index.aspx

${ }^{64}$ Obregón Loría fue propuesto como candidato para este premio por la Escuela de Historia y Geografía de la Universidad de Costa Rica y por la Facultad de Ciencias Sociales, apoyadas por otras instituciones según fuentes de Cultura Hispánica, como la Plaza de la Cultura, la Editorial Costa Rica y el Ministerio de Educación Pública. "Obregón Loría ganó premio Fernández Ferraz”, La Nación (23 de setiembre de 1985), s. p.
} 
Imagen 13

Premio Fernández Ferraz otorgado a Rafael Obregón Loría. La Nación, 23/09/1985.

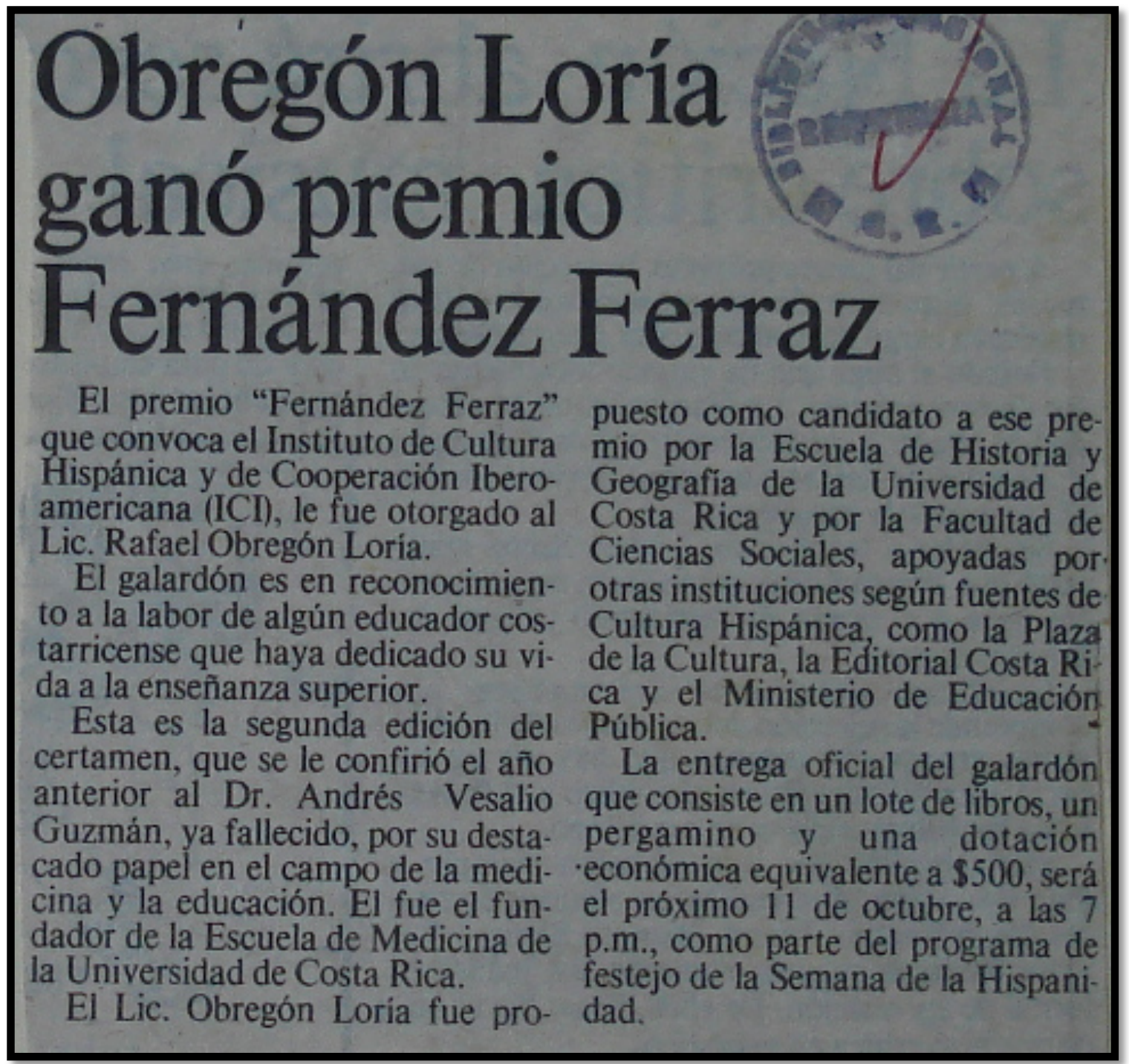

Fuente: Museo Histórico Cultural Juan Santamaría.

Un año más tarde, específicamente el 14 de agosto de 1990, en la Asamblea de la Escuela de Historia se aprobada por unanimidad la idea de evaluar una propuesta para otorgarle al profesor Obregón el Doctorado Honoris Causa. Este sentir obtuvo su beneplácito el 22 de mayo de $1991^{65}$, cuando por unanimidad ${ }^{66}$ el Consejo Universitario ratificó su aquiescencia a concederle el referido grado, el cual fue entregado cinco meses después, es decir, el 14 de octubre.

\footnotetext{
${ }^{65}$ Consejo Universitario, "Sesión 3738”, Universidad de Costa Rica (22 de mayo de 1991), 13-20.

${ }^{66}$ Gina Polini, "Pilar de la educación”, La Nación (15 de octubre de 1991), 2A.
} 


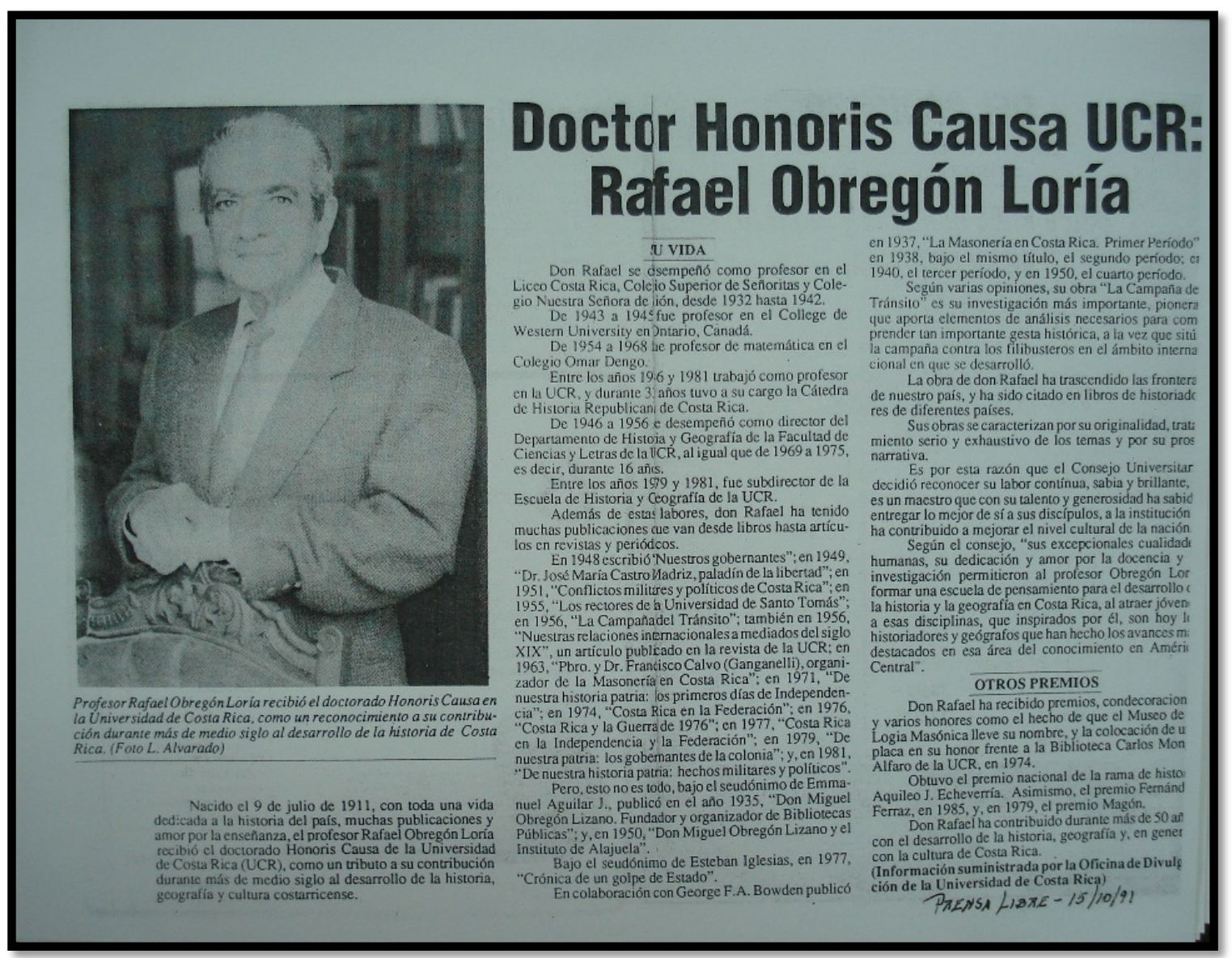

Fuente: Museo Histórico Cultural Juan Santamaría.

Dicho reconocimiento era justificado gracias a la asiduidad demostrada en su desempeño profesional, pues con su:

...labor continua, sabia y brillante, es un maestro que con su talento y generosidad ha sabido entregar lo mejor de sí a sus discípulos, a la institución, ha contribuido a mejorar el nivel cultural de la nación.

Según el consejo, "sus excepcionales cualidades humanas, su dedicación y amor por la docencia y la investigación permitieron al profesor Obregón Loría formar una escuela de pensamiento para el desarrollo de la historia y la geografía en Costa Rica, al atraer jóvenes a esas disciplinas, que inspirados por él, son hoy los historiadores y geógrafos que han hecho los avances más destacados en esa área del conocimiento en América Central"67.

67 "Doctor Honoris Causa UCR: Rafael Obregón Loría". 
Un aspecto que despuntaba en medio de estas múltiples conquistas y honras atribuidas a Obregón Loría era su personalidad sencilla; su modestia le hacía "esquivar reconocimientos y homenajes" "68. Al respecto Raúl Aguilar opina que "don Rafael recibía los premios, pero él fue muy moderado. No era una persona que anteponía su protagonismo. Él recibió todo con complacencia pero no era objeto de comentario"69. Por este motivo es que fue catalogado como un hombre sobrio que huía de la publicidad ${ }^{70}$.

Imagen 15

Homenaje póstumo a Rafael Obregón Loría

\begin{tabular}{|c|c|c|}
\hline 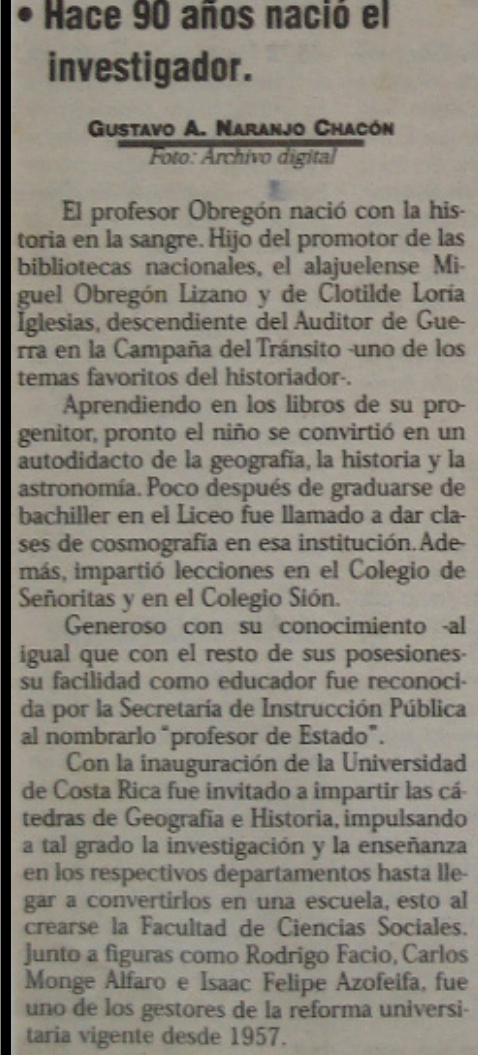 & $\begin{array}{l}\text { Rafael Obregón Loria, además de su in- } \\
\text { mensa labor de investigación, definio los } \\
\text { canones que guiaron a varias generaciones } \\
\text { de historiadores. } \\
\text { Primero en su clase } \\
\text { Cada vez que Rafael Obregón escogía } \\
\text { un tema, algo totalmente innovador y ori- } \\
\text { ginal surgiria de él. Francmasoneria, histo- } \\
\text { ria patria, educación, estudios militares, ge } \\
\text { nealogia: no existió una rama en la que no } \\
\text { llegara a destacar como investigador y di- } \\
\text { fusor, llegando a sumar la treintena de pro- } \\
\text { ducciones con su firma. } \\
\text { Humilde dentro de su vasto conoci- } \\
\text { miento, como director de la Escuela de }\end{array}$ & $\begin{array}{l}\text { Historia y Geografia el Maestro impulsó la } \\
\text { llegada de profesores extranjeros al pais - } \\
\text { como los reformadores Ciro Cardoso y } \\
\text { Héctor Pérez-y la salida de estudiantes al } \\
\text { extranjero por medio de becas, todo esto } \\
\text { con el fin de promover el cambio y la } \\
\text { constante revisión histórica a través de } \\
\text { nuevos ojos. } \\
\text { Su familiaridad y calidez en el trato } \\
\text { convirtieron al académico en uno de los } \\
\text { personajes más reconocidos y representa- } \\
\text { tivos para el hombre de a pie, gratificándo- } \\
\text { le a su vez con numerosos honores, entre } \\
\text { ellos los Premios Magón, Aquileo Echeve- } \\
\text { rria y Fernández Ferraz. La propia universi- } \\
\text { dad lo nombró profesor emérito y le otor- } \\
\text { gó el doctorado honoris causa. } \\
\text { Mucho del trabajo de Obregón no po- } \\
\text { dria haberse dado sin el apoyo incondicio- } \\
\text { nal de su esposa, la gran educadora Luz Ar- } \\
\text { gentina Brenes. Una de las maestras más } \\
\text { sobresalientes de nuestro pais, su diligen- } \\
\text { cia para inculcar el civismo y el amor pa- } \\
\text { trio a sus alumnos es tan legendaria como } \\
\text { la consideración integral que mostraba a } \\
\text { sus alumnos. Ella ejerció sus labores do- } \\
\text { centes en la Escuela Julia Lang, en la Bue- } \\
\text { naventura Corrales, en la Republica del Pe } \\
\text { rú y en la Juan Rudin. Casados por más de } \\
\text { medio siglo, ambos murieron el año pasat } \\
\text { do (2000) con apenas unas semanas de dit- } \\
\text { ferencia. }\end{array}$ \\
\hline
\end{tabular}

Fuente: Revista Abanico, La Prensa Libre (11 de julio de 2001).

\footnotetext{
${ }^{68}$ Bermúdez, "Adicto al girasol”, 30.

${ }^{69}$ Entrevista efectuada a Raúl Aguilar Piedra.

70 "Rafael Obregón Loría: un estudioso callado y de espíritu joven”, 1.
} 


\section{A manera de conclusión}

La prolífica vida de Rafael Obregón Loría estuvo marcada por sus distintas facetas: la del investigador profundo, escritor ameno, profesor incansable, masón destacado, hombre humilde y un humanista. Una persona que se dedicó a escudriñar la historia de nuestro país ${ }^{71}$.

Sus condiciones personales tuvieron un papel esencial en esta multiplicidad de destrezas: desde las circunstancias familiares que le propiciaron el desarrollo de su amor y avidez por los libros, hasta el aprovechamiento que hacía de las oportunidades y acontecimientos que se le iban presentando conforme crecía. De esta manera, Obregón se halló de forma tempranera enseñando, produciendo textos y relacionándose con las personalidades, grupos e instituciones de la sociedad costarricense de ese entonces.

A lo anterior se le debe aunar su visión a futuro, evidente por ejemplo en su apego a la Historia. En esta área Obregón Loría abrió dos frentes: el primero de ellos fue su aporte a la instrucción, evidente tanto en las instituciones de educación secundaria en un primer momento y, posteriormente, a través de la Universidad de Costa Rica.

Desde estos espacios tuvo la perspectiva de reconocer no sólo cuáles eran las necesidades presentes sino que además propuso soluciones. Muestra de lo anterior fue el estímulo que ofreció a la llegada de profesores del extranjero, así como la motivación que le brindó a los estudiantes para que se animaran a estudiar fuera del país ${ }^{72}$; todo esto como una manera de refrescar y renovar la disciplina en Costa Rica.

Por otro lado y como un segundo frente se halla la investigación. Obregón cumplió una función precursora en cuanto al trabajo de base se refiere -llevado a cabo con fuentes primarias- así como con la sistematización de la documentación. Con su accionar no sólo estaba reconstruyendo hechos históricos del pasado nacional, sino que simultáneamente estaba sentando las bases de la disciplina histórica actual.

Asimismo, su acuciosidad le abrió las puertas para que múltiples de sus textos fueran publicados por distintas editoriales; siendo una situación poco habitual para la época por la limitación tanto de recursos como de tecnología para la realización de trabajos de esta índole. No obstante, venció dichas limitantes gracias a "su originalidad, tratamiento serio y exhaustivo de los temas y por su prosa narrativa" $"$ presentes en sus obras; las que valga destacar fueron producidas mayormente "entre su 40-50 años de edad y luego, en forma poco usual, de los 75 años, casi hasta su muerte",74.

\footnotetext{
${ }^{71}$ Evelyn Ugalde, "Rafael Obregón: El historiador del siglo XX”, Revista Magisterio 12 (2000), 12.

${ }^{72}$ Naranjo Chacón. "Rafael Obregón Loría. La historia tal y como la conocemos", 4.

73 "Doctor Honoris Causa UCR: Rafael Obregón Loría".

${ }^{74}$ Mata, "Infatigable maestro", 14A.
} 
Obregón era una "institución en Historia"75. Él era -en palabras del historiador Carlos Meléndez- "el historiador de la época contemporánea más reconocido, sobre todo por su especialidad: la historia de la República. Yo diría que nadie más como él conoció a profundidad todo el proceso histórico de los siglos XIX y XX"76.

Obregón Loría era un "lúcido expositor y elocuente orador""77. aunado a su erudición y carisma, su disponibilidad para ayudar así como sus altas cualidades ${ }^{78}$ y tesón, lo convirtieron más que un profesor en un humanista, capaz de "hilar en el tiempo los hilos de nuestra historia Patria" ${ }^{, 79}$. Al respecto el también historiador Vladimir de la Cruz aseveró:

En la docencia universitaria hay distintas facetas en las que se proyecta el profesor: puede proyectarse en el conocimiento propiamente necesario para aprobar su curso, pero hay un conocimiento accesorio que es importante y es el conocimiento humanístico. En este sentido a mi parecer es donde más se proyecta don Rafael. Digamos que es un maestro en la historia de Costa Rica, pero además, en el campo humanístico es otro maestro ${ }^{80}$.

Esta reputación que se erigió y consolidó el profesor Rafael Obregón Loría no es de extrañar, pues desde muy joven decidió hacer suyo un pensamiento de Jules Michelet, el que adquirió un carácter cardinal tanto en su vida profesional como personal: "Conociendo bien la patria, se le ama mucho más".

\footnotetext{
${ }^{75}$ Entrevista efectuada a Raúl Aguilar Piedra.

${ }^{76}$ Kryssia Ortega y Paola Ramírez, "Historia de luto", La República (26 de abril del 2000), 2 A.

${ }^{77}$ Mata, "Infatigable maestro", 14A.

${ }^{78}$ Montero Ríos, "Rafael Obregón. Una luz que se apagó".

79 Astrid Fischel Volio, "Luto profundo", Diario Extra (2 de mayo del 2000), 14.

80 “Rafael Obregón: Si conociéramos nuestra historia seríamos mejores ciudadanos".
} 


\section{Imagen 16}

Noticia del deceso de Rafael Obregón Loría

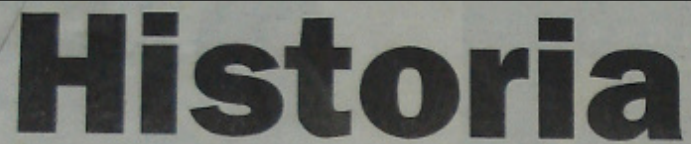

Las honras fúnebres del historiador Rafael Obregón se realizan hoy a las 11.30 a.m. en la capilla Don Bosco

\section{KRYSSIA ORTECA Y PAOLA RAMIREE}

La Repsiblica

Su vida se dividió entre dos pasiones: la historia y la masoneria, que unidas entre sí, solo pueden definir a un hombre con una profunda sed de conoci. miento. Ayer, a los 88 años mu-

ríó el historiador Rafael Obre gón Loría, debido a un paro respiratorio en el Hospital Calderón Guardia.

El origen de este paro fue un ataque de asma que sufrió en su casa, lo cual motivó su internamiento en dicho hospital la semana anterior, afirmó su hijo, Luis Obregón

Las honras fúmebres de este Premio Magón se realizan hoy a las 11.30 a.m. en la capilla Don Bosco y continuarán en el $\mathrm{Ce}$ menterio General. Antes de los actos religiosos habrá un home naje en la Universidad de Costs Rica (UCR) a las 7 a.m., y a las 9.30 a.m. su cuerpo pasará a la
Gran Logia.

Su partida deja un halo de tristeza en todos aquellos que lo conocieron y descubrieron jumto con él los misterios y detalles de la historia de Costa Rica, sin dejar de mencionar a quienes compartieron con él en la Logia Masónica

"Don Rafael es el historiador de la época contemporánea más reconocido, sobre todo por su especialidad: la historia de la República. Yo diría que nadie más como él conoció a profundidad todo el proceso histórico de los siglos XIX y XX", aseguró el historiador Carlos Melénde

"Yo fui su alumno y luego compañero por muchos años en la UCR y no hay duda de que sus lecciones fueron ejemplares y orientadoras en más de un sentido", agregó Meléndez.

Durante su vida como inves. tigador, Obregón también se destacó por su prolifica obra escrita, donde se incluyen o "La Campaña del Tránsito", que se refería a la guerra de 1856, y una serie de libros acerca de los poderes Legislativo y Judicial, comentó el historiador Luis Ferrero, su vecino de muchos años.

"Desde el punto de vista humano era muy cordial con todos. un amigo muy sincero. Fue mi

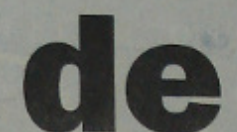

profesor y amigo por 40 años, y siempre estuvimos hermanados por el Premio Nacional de Cul ura Magón", dijo Ferrero.

Otra de sus cruzadas fue la organización del Museo Históri co Juan Santamaría de Alajue la.

Es un honor haber tenido un colaborador tan insigne como don Rafael. Le prestó grandes serviciosal museoy fue min des servicios al museo y fue mu generoso al donarle importante publicaciones para la biblioteca y otros objetos de interés para la historia", afirmó el director del Museo Histórico Juan Santamaría, Raúl Aguilar.

La mayor colaboración que hizo Obregon a este museo fue el libro "Familias alajuelenses en los libros parroquiales. Parroquia de Alajuela 1790-1900", una obra que requirió 19 años de trabajo investigativo, que consta de siete volúmenes y más de 6 mil páginas.

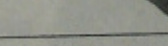

El prolifico historiador y reconocido masón, Rafael Obregón, murió ayer a los 88 años.

\section{Históricas letras}

Rafael Obregón escribió gran cantidad de libros, no solo de historia sino también acerca de masoneria, su otra pasión.

- "La masonería en Costa Rica" (Primer periodo 1865-1870), en 1938.

- "Doctor José María Castro Madriz", 1949.

"Actividades masónicas en Centroamerica antes en $1865^{\prime \prime}, 1965$.

"Conflictos militares y politicos "Costa Plica y la Guerra del se".
1976. "Costa Fica en la Independende Costa Rica", 195\%

\section{Recuento} de una vida

- Nació en San José en 1911

- Bachiller del Liceo de Costa Rica y posteriormente fue profesor gracias a su riguro sa formación académica au todidacta.

- Profesor en el Liceo de Costa Rica.

- Profesor y catedrático en la Universidad de Costa Rica.

- Diez veces Gran Maestro de la Gran Logia Masónica.

- Formador $y$ del Museo co que co que
se encuentra en la Gran Logia de San José.

Fuente: Sección Variedades. La República (26 de abril de 2000). 


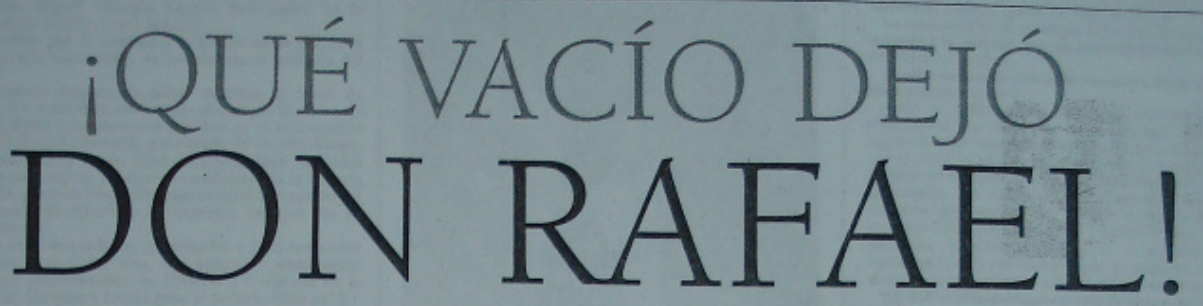

A Rafael Obregón Loría lo sobrevive una importantísima obra en historia y el recuerdo de un profesor entregado a su quehacer

Doriam Díaz Doriam Diaz

D afael Obregon LoZ $\begin{aligned} & \text { na vivio } 88 \text { anos } \\ & \text { y desde muy jo- } \\ & \text { vencito se dedios }\end{aligned}$ a contagiar con sus conocimientos a sus muchisimos lumnos, y a escribir $y$ hacer historia.

Su muerte, el martes pasado, propició una evaluacíón justa sobre su vida y Obra. Don Rafaci-como le dor profundo escritor ame. no, profesor incansable, masón destacado, hombre humilde y un humanists Con la asistencia de gra cantidad de amigos, parientes y exalumnos que llegaron a brindarle el ulumo adiós. el histonador fue enterrado el miercoles en el Cement no General de San josé. muchor, desde los profesores que consideran que fallecio nuestro histoniador del sigl. XX. hasta aquellos exalum nos que recuerdan al maestro ameno y muy insormadio. La pluma de don Rafact lue incansable. Exasten unos hos de ellos fundamentes para comprender la histors

\section{Algunos libros}

- Canfilictos militares y pointicos de Costa of-

- Los reciores de la Universidad de Santo to

- El presbitero y or. Francisco Calvo, organi zadar de la masonería en Costa Rica 10963 - Copder levisialiva en costa Rica $(1960)$. - Costa Rica y la guerra del 56 (1976). dias de nuestra independencián (1977)

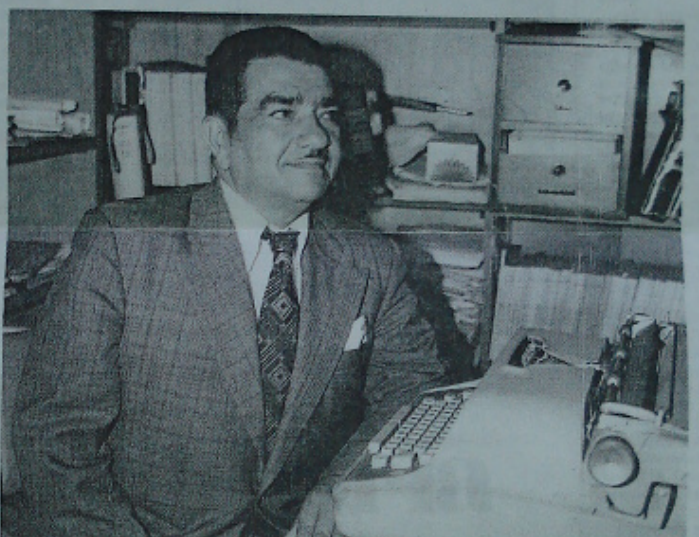

Con humildad y mucho trabajo. Rafael Obrepón Lorla se destacó en todos los campos que incursionó historia, la masonería y la investigación, entre otros

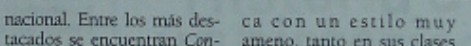
acados se encuentran Con- ameno, tanto en sus clases fictos militares y politicos de como en sus obras escerCosta Rica (1951), La Camparia del Transto (1956, reeRica y la guerna del 56 y Familtias alajuelenses en las libros parroquiales. Parroquita de Alajuela $1790-1900$ (siete tomos publicados entre 1993 1999

A el se le deben obras undamentales sobre 185 Mabre Jose Maria Castio dad de Santo Tomás, sob masoneria y sobre el padre Francisco Calvo. Fue un investigador serio y profundo cuyo proposito fue miento de la historia p ria", destaca el histo Yamileth Gonzale cerrectora de Investigacion

de la Universidad de Cosa Riea y discipula de Obre gon, destacó que ese prof
sor dejo una gran herence

en cuanto a dar a conocer los procesos politicos de ente importante. Comb-

\section{El gran maestro}

"El, ante todo, era profesor. Su calidad humana y gran cantidad de conousientos los transmitia en partir la informacion que conocia con sus alumnos", quien es historiadona y soObregon Loria fue hijo y Geografia, "Fue un padre fue el organizador de ba el momento en que la bibliotecas publicas $y$ un histonia en Costa Rica debia estudioso de la geografia renovarse y empezo a to (acional, por lo cual Ra. mentar los cambios", destauna escuela publica yen el ca Francisco Enriquez, ac Una escuela publica y en el tual direcor
Liceo de Costa Rica, se in- de Historia ereso desde muy joven Obregon Loria propició por leer acerca de geogra- la llegada de profesores exastronomia e histona. tranjeros al puis (como Ciro iceo fue llamado a dar extranjero por medio de de cosmografia en becas, todo esto con el fi mpartio lecciones en el Por anos, y sin que Colegio de Sethoritas y en tiempo de pensionarse lo quien es histonadora Poco despues de gra- Cardoso y tiector Perez) y

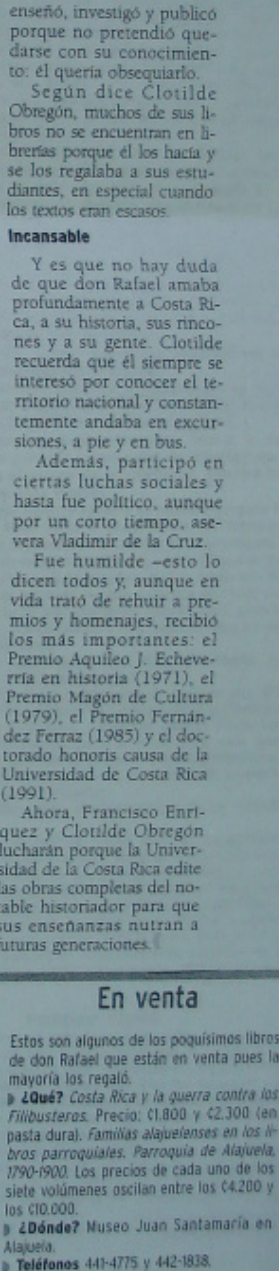




\section{Fuentes}

\section{Archivos y actas}

Archivo Nacional de Costa Rica (ANCR). Expedientes de matrimonios civiles 1209 (1943). Escuela de Historia. “Acta Sesión 38". Actas de la Asamblea de Escuela 1978. Escuela de Historia, Universidad de Costa Rica, 7 de diciembre de 1978.

Consejo Universitario. “Sesión 3738”. Universidad de Costa Rica, 22 de mayo de 1991.

\section{Periódicos y revistas}

Carvajal, Guillermo. "El Doctorado Honoris Causa para don Rafael Obregón Loría". Semanario Universidad. 14 de junio de 1991.

"Día histórico: Rafael Obregón Loría”. La Nación. 15 de setiembre de 1982.

Díaz, Doriam. “¿Qué vació dejó don Rafael!”. La Nación. Sección Viva. 29 de abril del 2000.

"Doctor Honoris Causa UCR: Rafael Obregón Loría". La Prensa Libre. 15 de octubre de 1991.

"Eran otros tiempos". La Nación. 1 de enero de 1975.

"Familias de los archivos parroquiales". Semanario Universidad. 15 de julio de 1994.

Fischel Volio, Astrid. "Luto profundo". Diario Extra. 2 de mayo del 2000.

G. de Mayer, Rosita. "Rafael Obregón: un valor nacional”. La Nación. $1^{\circ}$ de octubre de 1974.

Gólcher, Raquel. "UCR trata de modernizarse. VI Congreso Universitario”. La Nación. 14 de mayo del 2002. Disponible en http://www.nacion.com/ln_ee/2002/mayo/14/pais14.html

Mata, Leonardo. "Infatigable maestro". La Nación. 8 de mayo del 2000.

Montero Ríos, Patricia. "Rafael Obregón. Una luz que se apagó”. Semanario Universidad. 3 al 9 de mayo del 2000.

Mora, Guiselly. "Historia patria de luto. Murió Rafael Obregón Loría”. Al Día. 26 de abril del 2000.

Mora Rodríguez, Arnoldo. "La muerte de Rafael Obregón”. La República. 5 de mayo del 2000.

Muñoz Campos, Fabio. "Rafael Obregón Loría, Historia de un historiador". Contrapunto. 16 de marzo de 1980.

Naranjo Chacón, Gustavo. "Rafael Obregón Loría. La historia tal y como la conocemos". Revista Abanico. La Prensa Libre. 11 de julio del 2001.

“Obregón Loría ganó premio Fernández Ferraz”. La Nación. 23 de setiembre de 1985.

Ortega, Kryssia y Paola Ramírez. "Historia de luto”. La República. 26 de abril del 2000.

Polini, Gina. "Pilar de la educación". La Nación. 15 de octubre de 1991. 
"Rafael Obregón: Si conociéramos nuestra historia seríamos mejores ciudadanos". Forja. Suplemento cultural del Semanario Universidad. febrero 1980.

"Rafael Obregón Loría: un estudioso callado y de espíritu joven". La Nación. Sección Áncora. 3 de febrero de 1980.

"Rindieron homenaje a Rafael Obregón Loría". Semanario Universidad. 30 de noviembre al 6 de diciembre de 1979.

\section{Entrevista}

Entrevista efectuada a Raúl Aguilar Piedra. Director General del Museo Histórico Cultural Juan Santamaría. 22 de mayo del 2009.

\section{Bibliografía}

"Actualidad legislativa" (Disponible en http://www.asamblea.go.cr/actual/boletin/2000/abr00/25abr00.htm

Asamblea Legislativa. República de Costa Rica. "Beneméritos de la Patria, Miguel Obregón Lizano". 2009. Disponible en http://www.asamblea.go.cr/Centro_de_informacion/Sala_Audiovisual/Benemritos\% 20de\%201a\%20patria/Forms/DispForm.aspx?ID=33

Bermúdez, Mario. "Adicto al girasol”. Rumbo. 14 de abril de 1992.

Chaverri, Amalia. "Magón en el panorama cultural costarricense". Ministerio de Cultura y Juventud. 18 de julio de 2014. Disponible en http://www.mcj.go.cr/convocatorias_premios/magon/index.aspx

De Mora, Niní y María Molina de Lines. Rafael Obregón Loría. S. p. i., s.f., p. 5.

De la Cruz De Lemos, Vladimir. "R $\therefore$ H $\therefore \backslash$ Rafael Obregón Loría, Benemérito de la Masonería Costarricense, en el centenario de su natalicio". Revista Estudios 25, no. 1 (2012). Disponible en http://revistas.ucr.ac.cr/index.php/estudios/article/view/2721/2670

Mata, Leonardo. "Don Rafael Obregón Loría (1911-2000)". Diálogos Revista Electrónica de Historia 2, no. 1 (2001). Disponible en http://revistas.ucr.ac.cr/index.php/dialogos/article/view/6310/6012

Mena, Grethel, Luis Felipe Saravia y María de los Ángeles Solano. "Bio-bliografía Rafael Obregón Loría 1911-2000". Facultad de Educación, Escuela de Bibliotecología y Ciencias de la Información, Universidad de Costa Rica, 2001.

Méndez Alfaro, Rafael Ángel y Silvia Elena Molina Vargas eds. Rafael Obregón Loría. San José: UNED, 2010. 
Molina Jiménez, Iván. "Documentos y genealogías. A propósito de un libro de Rafael Obregón Loría y otro de Carlos Meléndez Chaverri”. Revista del Archivo Nacional LXI, no. 1-2 (1997): 68-72.

Obregón Loría, Rafael. Familias alajuelenses en los libros parroquiales. Parroquia de Alajuela. 1790-1900. Alajuela, Museo Histórico Cultural Juan Santamaría, 2003.

Porras León, Rita María. “Apuntes sobre el I Congreso Universitario". Oficina de Contraloría. Boletín 1-2002. artículo 2. Disponible en http://ocu.ucr.ac.cr/Boletines/2002-Boletin1-2.pdf

Ugalde, Evelyn. "Rafael Obregón: El historiador del siglo XX". Revista Magisterio 12 (2000): 12 .

\section{Anexo}

\section{Rafael Obregón Loría y su obra (1911-2000)}

\section{Libros}

Obregón Loría, Rafael. La Masonería en Costa Rica. San José: Imprenta Torno, 1938.

Obregón Loría, Rafael. La Masonería en Costa Rica. Segundo período. San José: Imprenta Trejos Hermanos, 1938.

Obregón Loría, Rafael. La Masonería en Costa Rica. Tercer período. San José: Trejos Hermanos, 1940.

Obregón Loría, Rafael. 75 aniversario de la fundación de la masonería en la República de Costa Rica. Logia Caridad No 26, 1865-1940. San José: Editorial Trejos, 1940.

Obregón Loría, Rafael. Ganganelli: organizador de la Masonería en Costa Rica. San José: Editorial Trejos, 1941.

Obregón Loría, Rafael. Album conmemorativo del 80 aniversario de la francmasonería en Costa Rica. San José: La Nación, 1945.

Obregón Loría, Rafael. Cosmografía. San José: Librería Atenea, 1946.

Obregón Loría, Rafael. Nuestros gobernantes. San José: Aurora Social, 1948.

Obregón Loría, Rafael. Dr. José María Castro Madriz: paladín de la libertad y de la cultura. San José: [s.n. La Nación], 1949.

Obregón Loría, Rafael. Nuestros gobernantes. San José: Imprenta Trejos, 1949.

Obregón Loría, Rafael y Borden, George F. A. La Masonería en Costa Rica: cuarto período. San José: Tormo, 1950.

Obregón Loría, Rafael. Conflictos militares y políticos de Costa Rica. San José: La Nación, 1951.

Obregón Loría, Rafael. José Quince Filguera, fundador de la Masonería en la República de Guatemala. San José: Imprenta Torno, 1951. 
Obregón Loría, Rafael. ¿Por qué se trasladó a Guatemala el Supremo Consejo Centroamericano? San José: Imprenta Tormo, 1952.

Obregón Loría, Rafael. Los Rectores de la Universidad de Santo Tomás de Costa Rica (Sección historia; no. 1). San José: Editorial Universitaria, 1955.

Obregón Loría, Rafael. La Campaña del tránsito: 1856-1857 (Sección historia; no. 2). San José: Editorial Universitaria, 1956.

Obregón Loría, Rafael. Apuntes resumidos de cosmografía. San José: Imprenta Torno, 1958.

Obregón Loría, Rafael. Apuntes relativos a la biblioteca de la Universidad. Costa Rica, 1960.

Obregón Loría, Rafael. Presbitero Doctor Francisco Calvo: Ganganelli, organizador de la masonería en Costa Rica. San José: Imprenta Borrasé, 1963.

Obregón Loría, Rafael. Actividades masónicas en Centro América antes de 1865. San José: Imprenta Tormo, 1965.

Obregón Loría, Rafael. De nuestra historia patria, Las autoridades coloniales superiores de Costa Rica. San José: Editorial desconocido, 1966.

Obregón Loría, Rafael. El Poder Legislativo en Costa Rica. San José: Imprenta Nacional, 1966.

Obregón Loría, Rafael. De nuestra historia patria, La caída de Carrillo. San José: Editorial desconocido, 1967.

Obregón Loría, Rafael. De nuestra historia patria, La segunda caída del doctor Castro. San José: Universidad de Costa Rica, 1968.

Obregón Loría, Rafael. De nuestra historia patria, Los sucesos de setiembre de 1821. San José: Universidad de Costa Rica, 1968.

Obregón Loría, Rafael. Costa Rica en la independencia y la Federación (Biblioteca patria; 8). San José: Editorial Costa Rica, 1969.

Obregón Loría, Rafael. De nuestra historia patria, El 27 de abril de 1870 y el gobierno de los 105 dias. San José: Universidad de Costa Rica, 1970.

Obregón Loría, Rafael. De nuestra historia patria, Movimientos antiespañolistas en Centro América. 1970.

Obregón Loría, Rafael. De nuestra historia patria, Los primeros días de independencia. (Serie historia y geografía; no. 10). San José: Publicaciones de la Universidad de Costa Rica, 1971.

Obregón Loría, Rafael. De nuestra historia patria, Costa Rica en la Federación (Serie Historia y Geografia; no. 20). San José: Publicaciones de la Universidad de Costa Rica, 1974.

Obregón Loría, Rafael. Costa Rica y la guerra del 56: la campaña del tránsito, 1856-1957. 2a. ed. San José: Editorial Costa Rica, 1976. 
Obregón Loría, Rafael. Costa Rica en la independencia y la Federación. San José: Editorial Costa Rica, 1977.

Obregón Loría, Rafael. De nuestra historia patria, Los gobernadores de la colonia. San José: Ciudad Universitaria Rodrigo Facio, Oficina de Publicaciones de la Universidad de Costa Rica, 1979.

Obregón Loría, Rafael, María del Rosario Molina Coto de Lines y Eugenio Rodríguez Vega. Antecedentes y creación de la Universidad de Costa Rica. San José: Universidad de Costa Rica, Instituto Centroamericano de Estadística, 1980.

Obregón Loría, Rafael y María Molina Coto de Lines et al. Rectores de la Universidad de Costa Rica. San Pedro: Oficina de Publicaciones de la Universidad de Costa Rica, 1980.

Obregón Loría, Rafael. De nuestra historia patria, Hechos militares y políticos. 2a. ed. Alajuela: Museo Histórico Cultural Juan Santamaría, 1981. Publicada anteriormente con el título de: Conflictos militares y políticos de Costa Rica.

Obregón Loría, Rafael. Hechos militares y políticos. San José: Imprenta Nacional, 1981.

Obregón Loría, Rafael. Costa Rica y la guerra del 56. 2a. ed. San José: Editorial Costa Rica, 1988.

Obregón Loría, Rafael. Costa Rica y la guerra contra los filibusteros. Alajuela: Museo Histórico Cultural Juan Santamaría, 1991.

Obregón Loría, Rafael. Genealogías de Alajuela (Letra A). Alajuela: Museo Histórico Cultural Juan Santamaría, 1a. ed., 1992.

Obregón Loría, Rafael. Familias alajuelenses en los libros parroquiales: Parroquia de Alajuela 1790-1900. Vol I, Letra A. Alajuela: Museo Histórico Cultural Juan Santamaría, 1993.

Obregón Loría, Rafael. El Poder Legislativo en Costa Rica. 2a. ed. San José: Asamblea Legislativa, 1995.

Obregón Loría, Rafael. Familias alajuelenses en los libros parroquiales: Parroquia de Alajuela 1790-1900. Vol II, Letras B y C. Alajuela y San José: Museo Histórico Cultural Juan Santamaría, Imprenta Nacional y Ministerio de Cultura Juventud y Deportes, 1995.

Obregón Loría, Rafael. Familias alajuelenses en los libros parroquiales: Parroquia de Alajuela 1790-1900. Vol III, Letras Ch, D, E, F, G. H, I. Alajuela y San José: Museo Histórico Cultural Juan Santamaría, Imprenta Nacional y Ministerio de Cultura Juventud y Deportes, 1995.

Obregón Loría, Rafael. Familias alajuelenses en los libros parroquiales: Parroquia de Alajuela 1790-1900. Vol IV, Letras J, L, M. Alajuela y San José: Museo Histórico Cultural Juan Santamaría, Imprenta Nacional y Ministerio de Cultura Juventud y Deportes, 1996. 
Obregón Loría, Rafael. Familias alajuelenses en los libros parroquiales: Parroquia de Alajuela 1790-1900. Vol V, Letras $N, O, P, Q, R$. Alajuela y San José: Museo Histórico Cultural Juan Santamaría, Imprenta Nacional y Ministerio de Cultura Juventud y Deportes, 1997.

Obregón Loría, Rafael. Familias alajuelenses en los libros parroquiales: Parroquia de Alajuela 1790-1900. Vol VI, Letras S, T, U. Alajuela y San José: Museo Histórico Cultural Juan Santamaría, Imprenta Nacional y Ministerio de Cultura Juventud y Deportes, 1997.

Obregón Loría, Rafael. Familias alajuelenses en los libros parroquiales: Parroquia de Alajuela 1790-1900. Vol VII, Letras V, W, Z. Alajuela y San José: Museo Histórico Cultural Juan Santamaría, Imprenta Nacional y Ministerio de Cultura Juventud y Deportes, 1999.

Obregón Loría, Rafael. Familias alajuelenses en los libros parroquiales: Parroquia de Alajuela 1790-1900. Vol VII. Datos excluidos de la exploración de 100 años de las familias alajuelenses, 1790-1900. Libros Parroquiales, Parroquia de Alajuela. Alajuela y San José: Museo Histórico Cultural Juan Santamaría y Ministerio de Cultura Juventud y Deportes, 2000.

Obregón Loría, Rafael, Teodoro Picado Michalski, y Manuel Araya Incera, Manuel eds. Relaciones internacionales y lucha contra los filibusteros. San José: Ministerio de Cultura, Juventud y Deportes, Comisión Nacional de Conmemoraciones Históricas, 2006.

Obregón Loría, Rafael. De nuestra historia patria, Causas de la independencia de las colonias españolas en América. Editorial desconocido, s. f.

Obregón Loría, Rafael. De nuestra historia patria, La caída de Carrillo. Inédito, 1967.

Obregón Loría, Rafael. "Doña Manuela Santamaría". Inédito, s. f.

Obregón Loría, Rafael et. al. Plan para elaborar una historia general de Costa Rica. San Pedro: Universidad de Costa Rica, s. f.

Obregón Loría, Rafael. Presbítero Dr. Francisco Calvo Gangelli. San José: Editorial desconocido, s. f.

Obregón Loría, Rafael, coord. La Historia como ciencia: plan para elaborar una historia general de Costa Rica. San Pedro, Montes de Oca, s. f. Universidad de Costa Rica, Facultad de Ciencias y Letras, Departamento de Historia y Geografía.

\section{Artículos de revistas}

Obregón Loría, Rafael. "Don José Comas Solá, ilustre astrónomo español”. Repertorio Americano 28, no. 8 (febrero, 1934): 116. 
Obregón Loría, Rafael. "Grandes figuras costarricenses Dr. don Eusebio Figueroa Oreamuno". Revista de los Archivos Nacionales 5, no. 9-10 (setiembre-octubre, 1941): 507-516.

Obregón Loría, Rafael. "Cuestiones históricas. Carta de don Rafael Obregón Loría".

Revista de los Archivos Nacionales 6, no. 1-2 (enero-febrero, 1942): 91-94.

Obregón Loría, Rafael, "El Dr. Figueroa y nuestra antigua universidad". Revista de los

Archivos Nacionales 6, no. 11-12 (noviembre-diciembre, 1942): 578-581.

Obregón Loría, Rafael. “Apuntes acerca de la masonería antigua en Costa Rica”. Revista de los Archivos Nacionales 8, no. 1-2 (enero-febrero, 1944): 29-48.

Obregón Loría, Rafael. "Estudio crítico sobre la partida de defunción de Juan Santamaría". Revista de los Archivos Nacionales 8, no. 3-4 (marzo-abril, 1944): 149-153.

Obregón Loría, Rafael. "Un ilustre rector de la Universidad de Santo Tomás, Dr. Rafael Nicolás Gallegos Castro". Revista de los Archivos Nacionales 8, no. 9-10 (setiembre-octubre, 1944): 531-533.

Obregón Loría, Rafael. "Dr. Francisco Chaves Castro: iniciador de la codificación de leyes en Costa Rica". Revista de los Archivos Nacionales 10, no. 7-8 (noviembrediciembre, 1946): 375.382.

Obregón Loría, Rafael. "El Dr. Castro, presidente educador”. Crónica 1, no. 6 (setiembre, 1948): 7.

Obregón Loría, Rafael. "Prócer costarricense sepultado en el océano Pacífico". Eureka 1, no. 5 (agosto, 1949): 5.

Obregón Loría, Rafael. "Lic. Vicente Sáenz Llorente”. Eureka 1, no. 6 (setiembre, 1949): 5. Obregón Loría, Rafael. “Dr. Eusebio Figueroa Oreamuno”. Eureka 1, no. 7 (octubre, 1949): 12.

Obregón Loría, Rafael. "Historia del Poder Ejecutivo”. La República (1952).

Obregón Loría, Rafael. "Historia del Poder Ejecutivo en Costa Rica”. Además, suplemento La República (noviembre, 1953-agosto, 1954).

Obregón Loría, Rafael. "Nuestras Bibliotecas antes de 1890". Boletín Asociación Costarricense Bibliotecarios 2-3 (1955): 4-20.

Obregón Loría, Rafael. "Zavala, el enfant terrible de la Guerra contra los filibusteros". Brecha 1, no. 2 (octubre, 1956): 6.

Obregón Loría, Rafael. "Nuestras relaciones internacionales a mediados del siglo XIX". Revista de la Universidad de Costa Rica 14 (1956): 63-140.

Obregón Loría, Rafael. “La Campaña del Tránsito”. Brecha 1, no. 5 (enero, 1957): 1-4.

Obregón Loría, Rafael. "Manuel Alvarado Barroeta”. Brecha 1, no. 12 (agosto, 1957): 4143.

Obregón Loría, Rafael. “Armas y letras de un soldado de Morazán”. Brecha 2, no. 9 (mayo, 1958): 3-5. 
Obregón Loría, Rafael. “La guarda del campamento”. Brecha 2, no. 12 (agosto, 1958): 1920.

Obregón Loría, Rafael. "La Universidad de Santo Tomás (1843-1888)". Revista de Filosofía de la UCR 3, no. 9 (1961): s. p.

Obregón Loría, Rafael, Abelardo Bonilla y Enrique Macaya. "Significación intelectual de la Universidad de Santo Tomás en la Costa Rica del siglo XIX”. Revista de Filosofía 3, no. 9 (enero-junio 1961): 79-93.

Obregón Loría, Rafael. “Gobierno de don Próspero Fernández Oreamuno: II Parte”. Revista del Archivo Nacional 1-12 (1993).

Obregón Loría, Rafael. "Gobierno de don Próspero Fernández (continuación): III Parte”. Revista del Archivo Nacional 1-12 (1994).

Obregón Loría, Rafael. "Significación intelectual de la Universidad de Santo Tomás en la Costa Rica del siglo XIX". Asociación Costarricense de Filosofía. Editorial Lehmann, s. f.

Obregón Loría, Rafael. “Apuntes Acerca de la Masonería Antigua en Costa Rica (18241865)". En Rafael Obregón Loría. Editado por Rafael Ángel Méndez Alfaro y Silvia Elena Molina Vargas. San José: UNED, 2010.

\section{Seudónimos}

Aguilar, Emmanuel. "Don Miguel Obregón Lizano: fundador y organizador de las Bibliotecas Pública”. 1935.

Aguilar, Emmanuel. "Don Miguel Obregón Lizano y el Instituto de Alajuela”. 1950.

Iglesias, Esteban. "Crónica de un golpe de Estado". 1977. 